\title{
Adaptation of the Patient Benefit Assessment Scale for Hospitalised Older Patients: Development, Reliability and Validity of the P-BAS Picture Version
}

\author{
Maria Johanna van der Kluit ( $\nabla$ m.j.van.der.kluit@umcg.nl ) \\ University of Groningen, University Medical Center Groningen, University Center for Geriatric Medicine \\ Geke J. Dijkstra \\ University of Groningen, University Medical Center Groningen, Department of Health Sciences, Applied Health Research \\ Sophia E. de Rooij \\ University of Groningen, University Medical Center Groningen, University Center for Geriatric Medicine
}

\section{Research Article}

Keywords: Older adults, Hospitalisation, Patient perspective, Goal setting, Patient-reported outcomes, Validity, Reliability, Responsiveness, Minimal Important Change (MIC), Value-Based Health Care

Posted Date: May 6th, 2021

DOI: https://doi.org/10.21203/rs.3.rs-477883/v1

License: (c) (1) This work is licensed under a Creative Commons Attribution 4.0 International License. Read Full License 


\section{Abstract}

Background: The Patient Benefit Assessment Scale for Hospitalised Older Patients (P-BAS HOP) is a tool developed to both identify the priorities of the individual patient and to measure the outcomes relevant to him/her, resulting in a Patient Benefit Index (PBI), indicating how much benefit the patient had experienced from the hospitalisation. The reliability and the validity of the P-BAS HOP appeared to be not yet satisfactory and therefore the aims of this study were to adapt the P-BAS HOP and transform it into a picture version, resulting in the P-BAS-P, and to evaluate its feasibility, reliability, validity, responsiveness and interpretability.

Methods: Process of instrument development and evaluation performed among hospitalised older patients including pilot tests using Three-Step TestInterviews (TSTI), test-retest reliability on baseline and follow-up, comparing the PBI with Intraclass Correlation Coefficient (ICC), and hypothesis testing to evaluate the construct validity. Responsiveness of individual P-BAS-P scores and the PBI with two different weighing schemes were evaluated using anchor questions. Interpretability of the PBI was evaluated with the visual anchor-based minimal important change (MIC) distribution method and computation of smallest detectable change (SDC) based on ICC.

Results: Fourteen hospitalised older patients participated in TSTIs at baseline and thirteen at follow-up after discharge. After several adaptations, the P-BAS$\mathrm{P}$ appeared feasible with good interviewer's instructions. The pictures were considered relevant and helpful by the participants. Reliability was tested with 41 participants at baseline and 50 at follow-up. ICC between $\mathrm{PBI}_{1}$ and $\mathrm{PBI}_{2}$ of baseline test and retest was 0.76 , respectively 0.73 . At follow-up 0.86 , respectively 0.85 .

For the construct validity, tested in 169 participants, hypotheses regarding importance of goals were confirmed. Regarding status of goals, only the followup status was confirmed, baseline and change were not. The responsiveness of the individual scores and PBI were weak, resulting in poor interpretability with many misclassifications. The SDC was larger than the MIC

Conclusions: The P-BAS-P appeared to be a feasible instrument, but there were methodological barriers for the evaluation of the reliability, validity, and responsiveness. We therefore recommend further research into the P-BAS-P.

\section{Background}

Quantitative outcomes of hospitalisation can be described with objective or subjective measures. Objective measures are, for example, length of stay, mortality, or clinical performance indicators. Subjective measures are patient-reported outcomes and are dependent on the judgment of the individual patient; examples are symptom burden, functional status, and health-related quality of life (1). However, patient-reported outcomes do not always reflect what patients find important since patient involvement in the development of instruments is rare (2). But even when patients are involved in the generation of outcomes, they often only reflect the priorities of the overall patient population and not of the individual patient, while which outcomes are considered important, differ per individual $(3,4)$. We therefore developed the Patient Benefit Assessment Scale for Hospitalised Older Patients (P-BAS HOP) (5).

\section{P-BAS HOP}

The P-BAS HOP was designed as a tool to inventory the personal goals and benefits of individual older hospitalised patients. The development and validation of the first version was published previously $(5,6)$. In brief: The P-BAS HOP is an interview-based questionnaire consisting of two parts: 1 ) a baseline questionnaire to select and assess the importance of various predefined personal goals derived from qualitative interviews with hospitalised older patients and 2) an evaluation questionnaire to assess the extent to which the hospital admission helped to achieve these individual goals. Based on these data an individual Patient Benefit Index (PBI) is computed, which is an overall value reflecting the achievement of the goals weighted by their importance. The baseline questionnaire consisted of two parts. In the first part, the interviewer listed subjects and the participant could indicate whether he experienced or expected limitations regarding that specific subject. In the second part, the participant was asked, for each subject identified in the first part, whether it was a goal for the current hospitalisation and, if so, how important this goal was.

The reliability and the validity of the P-BAS HOP appeared to be not yet satisfactory. We therefore recommended adapting the P-BAS HOP as follows: modify the first step in which the participant was asked whether he experienced a problem or limitation with a subject, differentiate between prevention, preservation and improvement, and remove the word 'again' in the questions. Also, reformulate the questions in the follow-up questionnaire or make clear to which timeframe they refer (6).

\section{Development P-BAS Picture Version}

To further enhance the understanding of the P-BAS HOP, as $29 \%$ of the Dutch population have limited health literacy, and this prevalence is higher among older people (7), also a picture version was made (8). All items were changed into drawings by a professional illustrator. These drawings were presented to older patients visiting or staying in the hospital to check comprehensibility and were modified when necessary. The final pictures were printed on plasticized cards. Initially, the original format was maintained in which first a selection was made of limitations on one side of the card and then a second part whether the applicable cards were a goal and, if so, how important this goal was. But a small pilot revealed that, although the cards were attractive to participants, the limitations found in the original format remained (6). We, therefore, decided to develop and test an adapted format.

\section{New Format of the P-BAS Picture Version (P-BAS-P)}

Definitions of the most relevant concepts applied in the P-BAS-P are provided in Table 1. 


\section{Baseline during Hospitalisation}

A set of cards with 21 possible goals, of each goal two identical cards, were presented to the participant. Two sheets with answer options were placed in front of the participant (Figure 1). The participant was asked per card whether this goal applied to him. When a goal did not apply or was not important for the participant, he/she placed the cards in the box 'not at all important/does not apply' of the 'importance sheet'. When the participant indicated that a goal applied to him/her, the following questions were answered (flexible order): 1) indicate the importance of the goal by placing the card in one of the boxes 'somewhat', 'quite' or 'very' important on the 'importance sheet'. 2) indicate how it was going on the day of admission with the particular subject by placing the card in one of the boxes 'very bad', 'bad', 'mediocre', 'satisfactory', 'good', 'very good' on the 'status sheet'. 3) indicate whether the goal is prevention/preservation or improvement, by turning up the blue side with =-sign or the green side with the $\uparrow$-sign. The exceptions were 'knowing what is wrong with me' and 'remaining alive'. Since for these two goals the options prevention/preservation or improvement were not applicable, these cards had no $=-$ or $\uparrow$-sign and had a yellow colour. In addition, for the goal 'remaining alive', only one card was available, since we only asked for the importance and not the status. The last cards depicted a question mark, allowing the participant the opportunity to add an extra personal goal. When all cards were placed, the interviewer wrote the answers on an answer sheet. The complete instructions and answer sheet are shown in Additional file 1.

\section{Follow-up}

During the follow-up, only goals applicable for that participant were evaluated. Two formats were tested:

Format one: the participant was asked what the status per item was at that moment with the answer options: 'very bad', 'bad', 'mediocre', 'satisfactory', 'good', 'very good'.

Format two: when the goal was prevention, the follow-up question was formulated as: 'Because of the hospitalisation.... was prevented', when the goal was preservation, the follow-up question was formulated as: 'Because of the hospitalisation, I still...', when the goal was improvement, the follow-up question was formulated as: 'Because of the hospitalisation, I can better/have more/am less... '. In all cases, the answer options were: 'not at all', 'somewhat', 'quite', 'completely'.

Table 1. Definitions of concepts in the P-BAS-P

\begin{tabular}{|c|c|}
\hline Concept & Definition \\
\hline Goal & Personal outcome a participant hopes to achieve with the hospitalisation. \\
\hline Importance & How important a goal is according to the participant, varying from not at all important to very important. \\
\hline Status & How is it going with a particular goal according to the participant, varying from very bad to very good. \\
\hline Prevention & Only used for symptoms. The goal of the participant is to prevent a symptom. \\
\hline Preservation & Used for all other goals. The goal is to preserve a function/condition. \\
\hline Improvement & The goal is to improve symptom/condition/functioning. \\
\hline Change & Difference in status between follow-up and baseline. \\
\hline Score (S) & $\begin{array}{l}\text { Component of the PBI. Combination of change and prevention/preservation or improvement. If the goal was prevention/preservation } \mathrm{S} \\
=\text { Change, if the goal was improvement } \mathrm{S}=\text { Change }-1 \text {. See section Responsiveness of the Score and PBIfor the full explanation. }\end{array}$ \\
\hline $\begin{array}{l}\text { Patient } \\
\text { Benefit Index } \\
\text { (PBI) }\end{array}$ & Overall value reflecting the achievement of goals weighted by their importance. \\
\hline
\end{tabular}

\section{Methods}

The steps used to develop and test the P-BAS-P are based on the steps of De Vet et al. (9) and outlined in Figure 2. After each step, the tool was modified. The steps are explained in the following sections.

\section{Pilot Test Baseline: Three-Step Test-Interview (TSTI).}

The first version was tested with the TSTI $(10,11)$. The TSTI is a type of cognitive interview useful for assessing how people interpret a questionnaire, its different items, and what types of strategies they use in responding to them. The TSTI consists of the following steps:

Step 1: Concurrent thinking aloud. The participant performed version 1 of the P-BAS-P with help of an interviewer while thinking aloud. The observer observed, made notes of the participant's behaviour (hesitations, corrections) and verbalised thoughts. However, the observer neither spoke nor intervened.

Step 2: Retrospective interview. The observer took over the interviewer role and aimed to fill in any gaps from the first step. Every behaviour and thought from the observation which the interviewer wanted further information about, was clarified.

Step 3: Semi-structured interview. An in-depth interview was conducted, aimed at eliciting participant's considerations and opinions. The participant was given an opportunity to explain behaviour, actions, or thoughts that he had in previous steps. The participant was asked his opinion about the tool and to explain his goals in his own words in order to perform a first content validation of the P-BAS-P. 


\section{Participants}

Eligible participants of the TSTI were 70 years and older; planned or unplanned hospitalised on medical or surgical wards of a university teaching hospital in the Netherlands; able to speak and understand Dutch and were without cognitive impairment. Inclusion criteria were verified with the staff nurse, and patients were then approached by the observer (MJvdK). Participants were completely anonymous, no list with names or other identifying data was made, nor did the researchers have access to medical records. Participants gave verbal consent to the interview and audio recording.

\section{Data Analysis}

Data gathering and data analysis were alternated. Interviews were audio recorded and transcribed verbatim. All remarks were then organised by question and step. After that, the data were coded by MJvdK and grouped into categories. The tool was adapted several times after the feedback until it was considered feasible and understandable.

\section{Field Test Baseline}

Version 2 was tested with a new group of hospitalised older patients. The aim of this field test was to train the research assistants in the use of the P-BAS-P and understand its feasibility.

\section{Participants}

Eligible participants were consecutive patients aged 70 years and older; planned or unplanned hospitalised on medical or surgical wards of a university teaching hospital, expected to stay for at least 48 hours; and a maximum of four days in hospital at the moment of interviewing; able to speak and understand Dutch and were without cognitive impairment. Inclusion criteria were verified with the staff nurse. Patients were approached by a trained research assistant and gave signed informed consent to participate.

\section{Pilot Test Follow-up: Three-Step Test-Interview (TSTI).}

The TSTI was repeated with the follow-up questionnaire four to ten weeks after discharge at the home of the participant with the two different formats described above.

The follow-up questionnaire was filled out in writing by the participant, in the presence of one observer/interviewer. Other steps and the analysis of the TSTI were conducted in the same manner as in step 2.

\section{Participants}

Participants included in the Field test Baseline (step 3) were approached during hospitalisation, received written information, and were asked permission to be approached after hospital discharge. From four weeks after discharge, participants were called to provide information again and to make an appointment if appropriate. Informed consent was signed at the home visit before the TSTI.

\section{Evaluating Reliability, Validity, Responsiveness, Interpretability}

This longitudinal study was performed among a new group of hospitalised older patients. The inclusion criteria were identical to step 3. The first face-toface interview took place in the first four days of hospitalisation. The follow-up interview was performed three months after discharge by telephone.

\section{Reliability}

Test-retest reliability of the baseline questionnaire was performed in a smaller group with an interval of one day, while the participant was still hospitalised. The participant was not notified in advance of the retest, but was asked for permission for another test on the other day.

Test-retest of the follow-up questionnaire was performed in another sample than the baseline test-retest with an interval of five to ten days. At the end of the first follow-up interview, participants were asked permission to be called back a week later to repeat some questions, without specifying which questions (only P-BAS-P). After the retest, the patient was asked whether anything had changed since the last test.

The PBI was calculated for both test and retest of baseline and follow-up and compared with 2-way random Intraclass Correlation Coefficient (ICC) for absolute agreement $(9,12)$. An ICC of at least 0.70 was considered reliable $(9,13)$.

\section{Validity}

For the construct validity, the questionnaires or constructs used are summarised in Table 2. Full details are given in Additional file 2.

Table 2. Constructs measured for the construct validity 


\begin{tabular}{|ll|}
\hline Construct & Operationalisation \\
\hline Appetite & Dutch VMS screening program (VMS) (14) \\
\hline Symptoms experienced on admission day & Rotterdam Symptom Checklist (RSCL) (15) \\
\hline Pain, experienced at moment of interview & Numeric rating scale (NRS) pain (0: no pain at all to 10: the worst imaginable pain) \\
\hline Fatigue, experienced at moment of interview & NRS fatigue (0: no fatigue at all to 10: the worst imaginable fatigue) \\
\hline Health-related quality of life at moment of interview & EQ-5D (16) \\
\hline Admission reason & Acute/ elective; diagnostic/ curative/ palliative \\
\hline Physical activity & Single question: 'How often are you physically active for at least 30 minutes?' with Likert scale \\
\hline Social functioning & 36-Item Short Form Survey Instrument (SF-36) - Social functioning (17) \\
\hline Goals on hospital admission & Open question: 'What do you hope to accomplish with this hospitalisation?' \\
\hline
\end{tabular}

Hypotheses Importance of the Goals. To test the construct validity of the importance of goals, we hypothesised that participants experiencing certain symptoms or limitations score higher on the importance of improving the related goal and that goals mentioned by participants after the open question were indicated as at least 'somewhat important' for the concerning goal. The specific goals we developed are listed in Table 3.

Analysis. Hypotheses 1 to 8 were evaluated using Cramér's V statistic. Hypotheses 9 to 11 were evaluated with Spearman's rank-order correlation. Since experiencing a symptom or restraint in a certain subject does not necessarily mean that this an (important) goal for hospital admission, hypotheses are confirmed if the correlation exceeds 'small' as defined by Cohen (18), meaning the correlation $>0.10$. Because the assumptions of Cramér's V statistic were not met because of too low (expected) cell prevalence, for these analyses, the categories 'somewhat' and 'quite important' were combined.

For hypothesis 12, a random selection of 50 cases was made and goals mentioned in the open question were coded using the item names of the P-BAS-P. When a participant mentioned a goal that was not in the P-BAS-P, it was coded as 'other'. The coding was done by two researchers independently and then compared and discrepancies were solved by consensus. Subsequently, the percentage of agreement between the codes and answers given in the P-BAS-P was calculated.

The importance of goals was considered valid if at least 75\%, thus nine of the first eleven hypotheses were confirmed and hypothesis 12 was confirmed in at least $75 \%$ of selected cases (13).

Table 3. Hypotheses importance of goals 


\begin{tabular}{|c|c|c|c|c|c|}
\hline \multicolumn{2}{|c|}{ Hypothesis } & \multirow{2}{*}{$\begin{array}{l}\text { Expected } \\
\text { correlation } \\
\text { Cramér's V >0.10 }\end{array}$} & \multicolumn{2}{|c|}{$\begin{array}{l}\text { Calculated } \\
\text { correlation } \\
\mathrm{n}\end{array}$} & \multirow{2}{*}{$\begin{array}{l}\mathrm{C} / \mathrm{R}^{*} \\
\mathrm{C}\end{array}$} \\
\hline 1 & $\begin{array}{l}\text { Participants who indicated a lack of appetite on the VMS and/or the RSCL are expected to assign } \\
\text { higher importance to the goal 'improving appetite'. }\end{array}$ & & 169 & 0.41 & \\
\hline 2 & $\begin{array}{l}\text { Participants who indicated tiredness and/or lack of energy on the RSCL are expected to assign } \\
\text { higher importance to the goal 'improving energy'. }\end{array}$ & Cramér's V >0.10 & 169 & 0.26 & $\mathrm{C}$ \\
\hline 3 & $\begin{array}{l}\text { Participants who indicated diarrhoea and/or constipation on the RSCL are expected to assign higher } \\
\text { importance to the goal 'improving bowel movements'. }\end{array}$ & Cramér's V >0.10 & 169 & n.c. & n.a. \\
\hline 4 & $\begin{array}{l}\text { Participants who indicated shortness of breath on the RSCL are expected to assign higher } \\
\text { importance to the goal 'reducing shortness of breath'. }\end{array}$ & Cramér's V >0.10 & 169 & 0.68 & $\mathrm{C}$ \\
\hline 5 & $\begin{array}{l}\text { Participants who indicated some problems or confined to bed on the EQ-5D mobility, are expected to } \\
\text { assign higher importance to the goal 'improving walking'. }\end{array}$ & Cramér's V >0.10 & 169 & 0.41 & $\mathrm{C}$ \\
\hline 6 & $\begin{array}{l}\text { Participants who indicated some problems or unable on the EQ-5D self-care, are expected to assign } \\
\text { higher importance to the goal 'improving washing/dressing'. }\end{array}$ & Cramér's V >0.10 & 169 & 0.37 & $\mathrm{C}$ \\
\hline 7 & $\begin{array}{l}\text { Participants who indicated some problems or unable on the EQ-5D usual activities, are expected to } \\
\text { assign higher importance for to goal 'improving hobbies'. }\end{array}$ & Cramér's V >0.10 & 166 & 0.37 & $\mathrm{C}$ \\
\hline 8 & $\begin{array}{l}\text { Participants who had an acute admission and/or a diagnostic admission reason, are expected to } \\
\text { assign higher importance to the goal 'knowing what is wrong with me'. }\end{array}$ & Cramér's V >0.10 & 161 & 0.20 & C \\
\hline 9 & $\begin{array}{l}\text { Participants with a higher NRS Pain, are expected to assign higher importance to the goal 'reducing } \\
\text { pain'. }\end{array}$ & Spearman's $>0.10$ & 164 & 0.34 & $\mathrm{C}$ \\
\hline 10 & $\begin{array}{l}\text { Participants with a higher score on the SF-36 - Social functioning, are expected to assign higher } \\
\text { importance to the goal 'improving visiting'. }\end{array}$ & Spearman's $>0.10$ & 164 & 0.19 & $\mathrm{C}$ \\
\hline 11 & $\begin{array}{l}\text { Participants with a lower score on the EQ-5D thermometer 'general health', are expected to assign } \\
\text { higher importance to the goal 'feeling better'. }\end{array}$ & $\begin{array}{l}\text { Spearman's }< \\
-0.10\end{array}$ & 168 & -0.05 & $\mathrm{R}$ \\
\hline 12 & $\begin{array}{l}\text { Goals that were mentioned after the open question, are, when applicable, indicated as minimum } \\
\text { 'somewhat important' for the concerning goal. }\end{array}$ & $\begin{array}{l}\text { Percentage of } \\
\text { agreement } \geq 75 \%\end{array}$ & 50 & $89 \%$ & C \\
\hline
\end{tabular}

$\mathrm{C}=$ confirmed $\mathrm{R}=$ Rejected

Hypotheses Status. To test the construct validity of the status of the P-BAS-P, we compared the status of the goals at baseline, follow-up, and change with other validated scales. The specific hypotheses we developed are listed in Table 4.

Analysis. Hypotheses were evaluated using Spearman's rank-order correlation. The P-BAS-P status and other constructs at follow-up both refer to the moment of the interview, while at baseline the P-BAS-P asks for the status on the day of admission and the other constructs for the moment of the interview, which is usually a few days later. Since the participant's situation can change a lot in that few days, we expect a lower correlation at baseline, and therefore the hypotheses are confirmed at baseline when the correlation $>0.20$ and on follow-up $>0.40$. For the change scores between follow-up and baseline, hypotheses were confirmed when the correlation $>0.30$. The status was considered valid if at least $75 \%$, thus six of the eight hypotheses of baseline, followup, and change, respectively, were confirmed (13).

Table 4. Hypotheses status baseline, follow-up, change 


\begin{tabular}{|c|c|c|c|c|c|c|c|c|c|c|c|c|c|}
\hline & & \multicolumn{4}{|c|}{ Baseline } & \multicolumn{4}{|l|}{ Follow-up } & \multicolumn{4}{|l|}{ Change } \\
\hline & & $\begin{array}{l}\text { Expected } \\
\text { correlation }\end{array}$ & $n$ & $\begin{array}{l}\text { Calculated } \\
\text { correlation }\end{array}$ & $\mathrm{C} / \mathrm{R}$ & $\begin{array}{l}\text { Expected } \\
\text { correlation }\end{array}$ & $\mathrm{n}$ & $\begin{array}{l}\text { Calculated } \\
\text { correlation }\end{array}$ & $\mathrm{C} / \mathrm{R}$ & $\begin{array}{l}\text { Expected } \\
\text { correlation }\end{array}$ & $\mathrm{n}$ & $\begin{array}{l}\text { Calculated } \\
\text { correlation }\end{array}$ & $\mathrm{C} / \mathrm{R}$ \\
\hline 1 & $\begin{array}{l}\text { There is a negative } \\
\text { correlation } \\
\text { between EQ-5D } \\
\text { mobility and status } \\
\text { for the goal } \\
\text { 'walking'. }\end{array}$ & $r s<-0.20$ & 108 & $r s=-0.27$ & $C$ & rs $<-0.40$ & 88 & $r s=-0.52$ & C & $r s<-0.30$ & 84 & $r s=-0.24$ & $\mathrm{R}$ \\
\hline 2 & $\begin{array}{l}\text { There is a negative } \\
\text { correlation } \\
\text { between EQ-5D } \\
\text { self-care and } \\
\text { status for the goal } \\
\text { 'washing/dressing'. }\end{array}$ & $r s<-0.20$ & 61 & $r s=-0.52$ & $C$ & $r s<-0.40$ & 55 & $r s=-0.74$ & C & rs $<-0.30$ & 47 & $r s=-0.42$ & C \\
\hline 3 & $\begin{array}{l}\text { There is a negative } \\
\text { correlation } \\
\text { between EQ-5D } \\
\text { usual activities and } \\
\text { status for the goal } \\
\text { 'hobbies'. }\end{array}$ & $\mathrm{rs}<-0.20$ & 77 & $r s=-0.33$ & C & $r s<-0.40$ & 62 & $r s=-0.33$ & $\mathrm{R}$ & $r s<-0.30$ & 55 & $r s=-0.31$ & C \\
\hline 4 & $\begin{array}{l}\text { There is a negative } \\
\text { correlation } \\
\text { between EQ-5D } \\
\text { pain/discomfort } \\
\text { and status for the } \\
\text { goal 'pain'. }\end{array}$ & $\mathrm{rs}<-0.20$ & 65 & $r s=-0.15$ & $\mathrm{R}$ & rs $<-0.40$ & 56 & $r s=-0.44$ & $\mathrm{C}$ & $r s<-0.30$ & 54 & $r s=-0.12$ & $\mathrm{R}$ \\
\hline 5 & $\begin{array}{l}\text { There is a positive } \\
\text { correlation } \\
\text { between EQ-5D } \\
\text { thermometer } \\
\text { 'general health' and } \\
\text { status for the goal } \\
\text { 'better'. }\end{array}$ & rs $>0.20$ & 148 & $\mathrm{rs}=0.19$ & $\mathrm{R}$ & rs $>0.40$ & 130 & $r s=0.62$ & $C$ & rs $>0.30$ & 127 & $r s=0.25$ & $\mathrm{R}$ \\
\hline 6 & $\begin{array}{l}\text { There is a negative } \\
\text { correlation } \\
\text { between the SF-36 } \\
\text { - Social } \\
\text { functioning and } \\
\text { status for the goal } \\
\text { 'visiting'. }\end{array}$ & $\mathrm{rs}<-0.20$ & 74 & $r s=-0.35$ & C & rs $<-0.40$ & 45 & $r s=-0.55$ & $C$ & rs $<-0.30$ & 41 & $r s=-0.16$ & $\mathrm{R}$ \\
\hline 7 & $\begin{array}{l}\text { There is a positive } \\
\text { correlation } \\
\text { between physical } \\
\text { activity and status } \\
\text { for the goal } \\
\text { 'sports'. }\end{array}$ & rs $>0.20$ & 68 & $r s=0.15$ & $\mathrm{R}$ & rs $>0.40$ & 45 & $\mathrm{rs}=0.20$ & $\mathrm{R}$ & rs $>0.30$ & 40 & $r s=-0.24$ & $\mathrm{R}$ \\
\hline 8 & $\begin{array}{l}\text { There is a negative } \\
\text { correlation } \\
\text { between NRS } \\
\text { Fatigue and status } \\
\text { for the goal } \\
\text { 'energy'. }\end{array}$ & $r s<-0.20$ & 137 & $r s=-0.10$ & $\mathrm{R}$ & $r s<-0.40$ & 116 & $r s=-0.60$ & C & rs $<-0.30$ & 109 & $r s=-0.22$ & $\mathrm{R}$ \\
\hline
\end{tabular}

$C=$ confirmed $R=$ Rejected

\section{Responsiveness of the Score and PBI}

The calculation of the PBI is based on the achievement of the set goals, weighted for their importance. For the achievement, a Score (S) is calculated based on the difference between status on follow-up and baseline and the choice between prevention/preservation or improvement. The goal is achieved when $S=$ 0 . When $S>0$, the goal is achieved beyond expectation, when $S<0$, the goal is not achieved. In case a goal was prevention or preservation, $S=0$ if no change occurred, so follow-up status - baseline status $=0$. When the goal was improvement, $S=0$ when the status improved, so follow-up status - baseline status $=1$. In other words: if the goal was prevention or preservation $S=$ follow-up status - baseline status, if the goal was improvement $S=$ follow-up status - baseline status - 1 . The only goal without grades in status is the goal remaining alive. If the participant set that goal, and is alive during follow-up, the participant receives standard Score 0 for that goal.

The $\mathrm{PBI}$ is then computed as follows: 
$P B I=\sum_{i=1}^{k} \frac{W_{i}}{\sum_{i=1}^{k} W_{i}} S_{i}$

with k weight-items $\left(W_{i}\right)$ and score-items $S_{i}($ range $-6-5)$

For the weight, we tested two weighting schemes to evaluate the role of the importance of the goals in the PBI. Option $1\left(\mathrm{PBI}_{1}\right)$ : linear: somewhat $=1$, quite $=$ 2 , very $=3$. Option $2\left(\mathrm{PBI}_{2}\right)$ : quadratic: somewhat $=1$, quite $=4$, very $=9$.

Hypotheses and Anchor Question. The following hypothesis was used to test the validity of the scores: Accomplishing goals noted on the open question correlate with the score on the P-BAS-P, if applicable. For this hypothesis, the same records were used as for hypothesis 12 regarding the importance of goals. For dyads with agreement between the code for the open question and the P-BAS-P item, the Spearman's rank-order correlation between the answer on the open question and the corresponding P-BAS-P score was calculated. A hypothesis was confirmed if the correlation $\geq 0.50$.

The following anchor question was used to validate the PBI: 'How much have you benefited from the admission?' With the following answer options: 'not at all', 'a little bit', 'somewhat', 'much, 'very much'. We also asked the participants for clarification of their answer.

The PBI is considered valid when it has a Spearman's correlation coefficient $\geq 0.50$ with the anchor question $(19,20)$. As the conclusion of how much benefit the participant had was not always based on achieved goals but could also be based on other indicators, for example, how kind the hospital staff was (6), we also calculated the Spearman's correlation coefficient for the selection of participants who based their anchor only on outcomes. We therefore coded explanations participants gave in 'based on outcomes', or 'based on other grounds'.

\section{Interpretability}

Interpretability is evaluated with the visual anchor-based minimal important change distribution method $(9,20)$. Participants who indicated: 'not at all', and 'a little bit', were considered as having no important benefit. Participants who indicated 'much' or 'very much', are considered as having important benefit. As it was not clear whether 'somewhat' was considered as important benefit or not, we labelled this as 'borderline'. Receiver operating characteristic (ROC) curves were used to determine optimal cut-off points for important and no important benefit.

To assess whether ROC cut-offs lay outside the measurement error, the smallest detectable change (SDC) was computed (9,21). The following formula was used: $S D C=S E M \times 1,96 \times \sqrt{2}$. Where SEM = Standard Error of Measurement, calculated as: $S E M=S D \sqrt{(1-I C C)}$, where $S D$ is the pooled standard deviation $(9,12,21)$. As we calculated reliability both at baseline and follow-up, but with different participants, we used the largest SEM for calculating SDC.

\section{Missing values}

When the P-BAS-P was not administered, this case was completely deleted. For all other missing values, we used pairwise deletion. For calculating the PBI only complete items were used, when only the importance was missing, the importance of these items was set on 'quite important'.

\section{Results}

\section{Pilot Test Baseline: Three-Step Test-Interview (TSTI)}

Twenty-five older hospitalised patients were approached for the TSTI of the baseline test and fourteen (56\%) agreed to participate. Characteristics of the participants are displayed in the second column of Table 5.

Table 5. Participants Three-Steps Test-Interview (TSTI) baseline and follow-up 


\begin{tabular}{|lll|}
\hline & $\begin{array}{l}\text { Baseline } \\
(\mathrm{n}=14)\end{array}$ & $\begin{array}{l}\text { Follow-up } \\
(\mathrm{n}=13)\end{array}$ \\
\hline Characteristic & $\mathrm{n}$ & $\mathrm{n}$ \\
\hline Gender & & \\
Male & 12 & 8 \\
Female & 2 & 5 \\
\hline Age (years) & & \\
70-79 & 9 & 9 \\
80-89 & 4 & 4 \\
$90-99$ & 1 & 0 \\
Educational level* & & \\
Low & 8 & 3 \\
Middle & 2 & 5 \\
High & 3 & 5 \\
Unknown & 1 & 0 \\
Admission reasont & & 0 \\
Pulmonary problems & 5 & 0 \\
Cardiac problems & 4 & 8 \\
Bowel problems & 2 & 3 \\
Kidney problems & 2 & 0 \\
Stroke & 0 & \\
General malaise & 1 & \\
\hline
\end{tabular}

* Educational level: Low= no education, primary school, basic vocational training; Middle = secondary education, vocational training; High = bachelor, master

† Reason according to the patient

Comprehension of the format varied widely between participants. Some participants needed only a short introduction and an example and were then able to place the cards independently in the boxes with only a little guidance from the interviewer, whereas others needed constant guiding and reminding of the aim. Some of these participants had the tendency to elaborate on how they were coping with the subject on the card without specifying whether it was a goal or not. This emphasized the necessity for adequate interviewer instructions and an instruction guide for the interviewers.

An example of guiding by the interviewer:

Washing and dressing. Is that a goal for you with this hospitalisation?

Yes, that you can still do that yourself.

Yes. And, uh.

I find that somewhat important.

Somewhat important. Because how is it going with washing and dressing now?

It is still fine, but with difficulty.

Yes. Satisfactory or good?

Let's say satisfactory.

And is it your goal to preserve it that way or to improve it?

To preserve it that way, yes. (P1)

Example of a participant with the tendency to elaborate on how he was coping with the subject, without specifying whether it was a goal: 
Well, the next one depicts a figure with a lot of pain, I can say that I have a lot of pain, but I have, I don't feel pain that easily. But when I move, I do feel pain now. And you have to indicate that here in points, I have always found that very difficult to interpret, but eh, I, I say, I, I, when I lay down it is not too bad and when I move, it hurts, I'm in the midst of it. So I have pain.

Yes. Yes. And is it a goal for you to reduce this?

Yes! Otherwise I will die. (laughing) (P7)

\section{Adaptations}

The following adaptations were made to the format:

Originally we had four answer options: 'bad, mediocre, satisfactory, good', but this appeared insufficient for some participants. We therefore added 'very bad' and 'very good'.

Initially, we had one card for each goal and one answering sheet with a horizontal axis for status and a vertical axis for importance where the participant could place the card. Since this appeared complicated for participants, we made two different answer sheets: one for status, and one for importance. The participant had two cards per goal and placed one card on each sheet, as explained in the methods.

Since most interviews were conducted after a few days of hospitalisation, the question about status was sometimes problematic. As some participants indicated that complaints had already improved compared to the day they were admitted, they had the goal 'improving', but their status was 'good' or 'very good' at the moment of interview. We therefore decided to ask in these cases how the status was on the day of admission.

We changed the text on the card 'visiting'. Originally we had the text 'visiting family or friends', but some participants started elaborating about family and friends that had passed away. To help them focus only on visiting, we changed the text into 'visiting'.

A user guide was written for the interviewers.

\section{Opinions of participants}

A broad variety of evaluations by participants included: pleasant diversion; nice pictures; emotional to be confronted with own impairments; subjects were considered very relevant; it was helpful to express wishes and concerns; interesting; and somewhat tiring.

\section{Content validity}

The goals the participants mentioned in their own words were indicated in the tool as at least 'somewhat important' in all cases. For example:

If you had to say in your own words what you hope to accomplish with this hospitalisation, what would you say?

Ehm, first of all, the solution to the pain that I was talking about, which is what I actually come here for. And so, as far as the physiotherapy is concerned, also that eh, the moving around, the moving around. (...) Then I just mean, uh, walking. Not those short distances like in the house, that, like this here, that's okay. Like this short distance, I could do that without a walker. But walking further, I mean that way. (...) Also in terms of breathing and so on. In regards to breathing, I will have to wait and see. I'm dreading it, but, uh, it's at least worth a try. (P11)

This participant indicated: Pain: very important, mediocre, improvement; Walking: very important, mediocre, improvement; Shortness of breath: very important, bad, improvement.

\section{Field Test Baseline}

Research assistants practised with Version 2 of the P-BAS-P in a new group of 62 consecutive hospitalised older patients. Sample characteristics are shown in the second column of Table 6 . Through observation and feedback it was revealed that the instruction to ask for the status on the day of admission when the interview was conducted after a few days and the status of the participant had changed, was not clear for all research assistants. We therefore decided to change the instructions and always ask for the status on the day of admission.

Table 6. Sample characteristics Field test baseline and Evaluation reliability, validity, responsiveness, interpretability 


\begin{tabular}{|c|c|c|}
\hline & $\begin{array}{l}\text { Field test baseline } \\
(n=62)\end{array}$ & $\begin{array}{l}\text { Evaluation reliability, validity, responsiveness, interpretability } \\
(n=169)\end{array}$ \\
\hline Characteristic & $\mathrm{n}(\%)$ & $\mathrm{n}(\%)$ \\
\hline \multicolumn{3}{|l|}{ Gender } \\
\hline Male & $37(60)$ & $96(57)$ \\
\hline Female & $25(40)$ & $73(43)$ \\
\hline Age (years), median (range) & $74(70-96)$ & $75(70-98)$ \\
\hline \multicolumn{3}{|l|}{ Living situation } \\
\hline Independent & $61(98)$ & $162(96)$ \\
\hline Sheltered accommodation & 0 & $4(2)$ \\
\hline Senior home & $1(2)$ & $2(1)$ \\
\hline Nursing home & 0 & $1(1)$ \\
\hline \multicolumn{3}{|l|}{ Educational level* } \\
\hline Low & $10(16)$ & $61(36)$ \\
\hline Middle & $37(60)$ & $65(38)$ \\
\hline High & $15(24)$ & $43(25)$ \\
\hline \multicolumn{3}{|l|}{ Specialty } \\
\hline Medical & $19(31)$ & $78(46)$ \\
\hline Surgical & $21(34)$ & $36(21)$ \\
\hline Intervention cardiology & $18(29)$ & $48(28)$ \\
\hline Unknown & $4(6)$ & $7(4)$ \\
\hline \multicolumn{3}{|l|}{ Admission type } \\
\hline Acute & $32(52)$ & $75(44)$ \\
\hline Elective & $26(45)$ & $87(52)$ \\
\hline Unknown & $4(6)$ & $7(4)$ \\
\hline Admission time (days) median (range) & $4(1-28)$ & $5(1-35)$ \\
\hline \multicolumn{3}{|c|}{$\begin{array}{l}\text { Number of days the interview took place after } \\
\text { admission }\end{array}$} \\
\hline \multicolumn{2}{|c|}{10 (6) } & $10(6)$ \\
\hline \multirow{3}{*}{3} & $28(45)$ & $64(38)$ \\
\hline & $24(40)$ & $69(41)$ \\
\hline & $8(13)$ & $26(15)$ \\
\hline
\end{tabular}

* Educational level: Low= no education, primary school, prevocational education; Middle = secondary or vocational education; High = bachelor, master

\section{Pilot Test Follow-up: TSTI}

Eighteen participants were approached in the hospital, and 17 gave permission to be contacted after discharge. Afterward, two participants refused, one participant appeared too confused for informed consent, and for one participant the opportunity to make an appointment fell outside the timeframe; this resulted in thirteen (72\%) participants for the TSTI of the follow-up. Characteristics of participants are displayed in the last column of Table 5.

As described in the Methods section, two formats were tested. Format one: the participant was asked what the status per item was at that moment. Format two started with 'Because of the hospitalisation...' and the rest of the sentence depended on the goal being 'prevention', 'preservation', or 'improvement'.

Format one was well understood, and answers were given easily. The only confusion was caused by the question 'How is your disease or condition now?'; as many participants have multiple, it was not clear for all which one was meant. We therefore made the addition: 'as concerning the disease or condition you were admitted for', which was well-understood.

Format two was more problematic. Participants often had to read the sentence several times before it was understood. Some other problems: 
Originally the follow-up question in the case of preservation was formulated as: 'Because of the hospitalisation, I still...' This caused confusion when the participant already had a low level of baseline function. We therefore changed the sentence into 'Because of the hospitalisation I maintained...'. Although this gave sometimes complicated sentences, it was better understood.

The question 'Because of the hospitalisation I remained alive' was often considered complicated. For example:

Yes, so I don't know, if I had surgery or not, if I would not have had surgery, whether I then, whether that was life-threatening. I don't know. (P8)

The use of the answer option 'somewhat' was interesting, since it was used with many intentions. Often it meant 'I don't know', or 'actually it is going really badly, but I stay hopeful', or 'I don't want to be too negative'. Only in a minority of the cases was it used to indicate 'I accomplished my goal to some extent'.

The main concern with format two was that it was unclear which timeframes the participant had to compare. Sometimes participants were evaluating the period in hospital, sometimes shortly after discharge. But even when participants evaluated their current situation, it was not clear with which period they had to compare, this could be long before hospitalisation, shortly before hospitalisation, or during hospitalisation. Changing the words 'because of' into 'thanks to, did not help.

Example:

Thanks to hospitalisation I have more energy. Well, no more energy. When I compare that with the situation before that time. Well, well, not more. Well, somewhat maybe. Yes... It depends on what I'm comparing it to, by the way. If it was right before my hospital admission, then of course it is eh... then it is completely. But if I go a little further back in time, it is not even that big of a difference. So I find it a little bit difficult to answer, this question. Let me answer it as quite. But more because I don't know at what point in time I have to compare it to. (P13)

Because of the difficulties with format two, we decided to continue only with format one.

\section{Evaluating Reliability, Validity, Responsiveness, Interpretability}

Version 3 of the P-BAS-P consisted of the baseline version with changed instructions and follow-up version format one.

\section{Sample}

From the 699 eligible patients, 363 were approached for informed consent and 179 gave it. After exclusion of ten cases, we had 169 baseline cases. We lost 29 to follow-up and an additional four the P-BAS-P were not administered at follow-up, which resulted in 136 follow-up cases. Full details are shown in Figure 3. Most (41\%) baseline interviews were done on the third day after admission.

Sample characteristics are shown in the last column of Table 6, and Additional File 3 shows the scores of the other questionnaires applied for evaluating construct validity.

\section{Descriptive statistics P-BAS-P}

In two cases the pictures were not used. One case was because there was no table available, and the other because the participant had to lie down completely flat. In both of these cases, the interviewer asked them all questions without using the cards. The time to conduct the P-BAS-P varied from six to 21 minutes, with a mean of eleven minutes.

Table 7 shows the baseline descriptive statistics of the P-BAS-P. The number of goals selected as a minimum of 'somewhat important' varied from 3 to 21 per person, with a median of 12 and a mean of 11.7. Twenty-eight participants mentioned an extra goal. Examples were: going on holiday, resuming (volunteer) work, or shopping. The missing values at baseline are all due to the interviewer accidentally forgetting to indicate the option on the answer sheet after the interview, except for one participant who did not know to indicate how important the goal 'enjoying life' was to him.

Table 8 shows the follow-up descriptive statistics and change scores of the P-BAS-P. Since the end of March 2020, the Corona-pandemic influenced answers on the items groceries, sports, hobbies, outings, visiting, and 'extra'. In cases where participants could not answer this question or indicated the answer was influenced by the Corona-measures, the answer was replaced by 'missing due to Corona'. A closer look at the other missing values revealed some patterns: In four cases the participant did not know the answer, for example the bowel movements were too irregular, or the participant was still under treatment and did not know to indicate what the disease status was. There were some seasonal problems: at the follow-up moment, it was not the right season for gardening $(1 \mathrm{x})$ or the hobby 'fishing' (3x). More difficult to interpret were participants stating they did not do an activity, for example: 'my husband does the groceries' (1x), 'I don't work in the garden' (3x), 'I don't sport' (4x), 'we don't go on outings' (2x), 'I have no hobbies anymore' (1x), 'I am not allowed to drive' (1x). It is unsure whether this meant the participant did not reach the goal, so the answer should be 'very bad', since the participant mentioned, for example, it was important to garden, and now he does not garden, or whether there was another reason not to garden. In three cases it is doubtful whether the goal selected on baseline was appropriate since the participant stated at follow-up 'I have never sported/made outings/visited'. One extra goal had a missing value since the goal was 'becoming 100', while the participant was 73 years on baseline.

Table 7. P-BAS-P Baseline descriptive statistics $n=169$ 


\begin{tabular}{|c|c|c|c|c|c|c|c|c|c|c|c|c|c|c|}
\hline & Importance & & & & & $\begin{array}{l}\text { Preventio } \\
\text { preservat } \\
\text { improvem }\end{array}$ & & Statu & & & & & & \\
\hline & $\begin{array}{l}\text { Not at all/ } \\
\text { not } \\
\text { applicable } \\
\text { n (\%) }\end{array}$ & $\begin{array}{l}\text { Some- } \\
\text { what } \\
\text { n (\%) }\end{array}$ & $\begin{array}{l}\text { Quite } \\
\mathrm{n}(\%)\end{array}$ & $\begin{array}{l}\text { Very } \\
n \\
(\%)\end{array}$ & $\begin{array}{l}\text { Mis- } \\
\text { sing }\end{array}$ & $\begin{array}{l}\text { Improve- } \\
\text { ment } \\
\mathrm{n}(\%)\end{array}$ & $\begin{array}{l}\text { Mis- } \\
\text { sing }\end{array}$ & $\begin{array}{l}\text { Very } \\
\text { bad }\end{array}$ & Bad & Mediocre & $\begin{array}{l}\text { Satisfac- } \\
\text { tory }\end{array}$ & Good & $\begin{array}{l}\text { Very } \\
\text { good }\end{array}$ & $\begin{array}{l}\text { Mis- } \\
\text { sing }\end{array}$ \\
\hline Better & $9(5)$ & $4(2)$ & $\begin{array}{l}39 \\
(23)\end{array}$ & $\begin{array}{l}117 \\
(69)\end{array}$ & 0 & $148(88)$ & 0 & $\begin{array}{l}15 \\
(9)\end{array}$ & $\begin{array}{l}49 \\
(31)\end{array}$ & $58(37)$ & $17(11)$ & $\begin{array}{l}18 \\
(11)\end{array}$ & $2(1)$ & 1 \\
\hline Energy & $29(17)$ & $11(7)$ & $\begin{array}{l}52 \\
(31)\end{array}$ & $\begin{array}{l}77 \\
(46)\end{array}$ & 0 & $121(86)$ & 0 & $\begin{array}{l}19 \\
(14)\end{array}$ & $\begin{array}{l}44 \\
(31)\end{array}$ & 47 (34) & $18(13)$ & $8(6)$ & $4(3)$ & 0 \\
\hline Pain & $100(59)$ & $7(4)$ & $\begin{array}{l}19 \\
(11)\end{array}$ & $\begin{array}{l}43 \\
(35)\end{array}$ & 0 & $59(86)$ & 0 & $\begin{array}{l}12 \\
(17)\end{array}$ & $\begin{array}{l}26 \\
(38)\end{array}$ & $20(29)$ & $2(3)$ & $6(9)$ & $3(4)$ & 0 \\
\hline $\begin{array}{l}\text { Bowel } \\
\text { movements }\end{array}$ & 141 (83) & $5(3)$ & $\begin{array}{l}11 \\
(7)\end{array}$ & $\begin{array}{l}12 \\
(7)\end{array}$ & 0 & $19(68)$ & 0 & $1(4)$ & $\begin{array}{l}11 \\
(39)\end{array}$ & $5(18)$ & $1(4)$ & $8(5)$ & $2(1)$ & 0 \\
\hline $\begin{array}{l}\text { Shortness } \\
\text { of breath }\end{array}$ & $71(42)$ & $3(2)$ & $\begin{array}{l}27 \\
(16)\end{array}$ & $\begin{array}{l}68 \\
(40)\end{array}$ & 0 & $91(93)$ & 0 & $\begin{array}{l}12 \\
(13)\end{array}$ & $\begin{array}{l}42 \\
(43)\end{array}$ & $30(31)$ & $4(4)$ & $9(9)$ & $1(1)$ & 0 \\
\hline Walking & $60(36)$ & $5(3)$ & $\begin{array}{l}37 \\
(22)\end{array}$ & $\begin{array}{l}66 \\
(39)\end{array}$ & 1 & $93(85)$ & 0 & $\begin{array}{l}14 \\
(13)\end{array}$ & $\begin{array}{l}45 \\
(42)\end{array}$ & $28(26)$ & $9(8)$ & $8(7)$ & $4(4)$ & 1 \\
\hline Appetite & $126(75)$ & $5(3)$ & $\begin{array}{l}24 \\
(14)\end{array}$ & $\begin{array}{l}14 \\
(8)\end{array}$ & 0 & $27(63)$ & 0 & $3(7)$ & $\begin{array}{l}9 \\
(21)\end{array}$ & $14(33)$ & $4(9)$ & $\begin{array}{l}12 \\
(28)\end{array}$ & $1(2)$ & 0 \\
\hline $\begin{array}{l}\text { Knowing } \\
\text { what is } \\
\text { wrong }\end{array}$ & $111(66)$ & $2(1)$ & $\begin{array}{l}14 \\
(8)\end{array}$ & $\begin{array}{l}41 \\
(24)\end{array}$ & 1 & n.a. & n.a. & $\begin{array}{l}8 \\
(14)\end{array}$ & $\begin{array}{l}11 \\
(19)\end{array}$ & $18(32)$ & $8(14)$ & $\begin{array}{l}9 \\
(16)\end{array}$ & $3(5)$ & 1 \\
\hline Curing & $10(6)$ & $8(5)$ & $\begin{array}{l}39 \\
(23)\end{array}$ & $\begin{array}{l}111 \\
(66)\end{array}$ & 1 & $123(79)$ & 4 & $\begin{array}{l}15 \\
(10)\end{array}$ & $\begin{array}{l}46 \\
(29)\end{array}$ & 69 (44) & $15(10)$ & $\begin{array}{l}10 \\
(6)\end{array}$ & $3(2)$ & 1 \\
\hline Alive & $21(12)$ & $12(7)$ & $\begin{array}{l}21 \\
(12)\end{array}$ & $\begin{array}{l}115 \\
(68)\end{array}$ & 0 & n.a. & n.a. & n.a. & n.a. & n.a. & n.a. & n.a. & n.a. & n.a. \\
\hline Enjoy & $52(31)$ & $11(7)$ & $\begin{array}{l}41 \\
(24)\end{array}$ & $\begin{array}{l}64 \\
(38)\end{array}$ & $1 *$ & $76(65)$ & 0 & $6(5)$ & $\begin{array}{l}20 \\
(17)\end{array}$ & $33(28)$ & $23(20)$ & $\begin{array}{l}24 \\
(21)\end{array}$ & $\begin{array}{l}10 \\
(9)\end{array}$ & 1 \\
\hline Groceries & $81(48)$ & $11(7)$ & $\begin{array}{l}44 \\
(26)\end{array}$ & $\begin{array}{l}33 \\
(20)\end{array}$ & 0 & $53(60)$ & 0 & $\begin{array}{l}11 \\
(13)\end{array}$ & $\begin{array}{l}20 \\
(23)\end{array}$ & $25(28)$ & $4(5)$ & $\begin{array}{l}23 \\
(26)\end{array}$ & $5(6)$ & 0 \\
\hline $\begin{array}{l}\text { Wash and } \\
\text { dress }\end{array}$ & $108(64)$ & $2(1)$ & $\begin{array}{l}28 \\
(17)\end{array}$ & $\begin{array}{l}31 \\
(18)\end{array}$ & 0 & $27(44)$ & 0 & $4(7)$ & $\begin{array}{l}11 \\
(18)\end{array}$ & $11(18)$ & 7 (12) & $\begin{array}{l}21 \\
(34)\end{array}$ & $\begin{array}{l}7 \\
(12)\end{array}$ & 0 \\
\hline Garden & $109(65)$ & $11(7)$ & $\begin{array}{l}23 \\
(14)\end{array}$ & $\begin{array}{l}26 \\
(15)\end{array}$ & 0 & $46(77)$ & 0 & $3(5)$ & $\begin{array}{l}21 \\
(35)\end{array}$ & $13(22)$ & $8(13)$ & $\begin{array}{l}14 \\
(23)\end{array}$ & $1(2)$ & 0 \\
\hline Sports & $98(58)$ & $13(8)$ & $\begin{array}{l}29 \\
(17)\end{array}$ & $\begin{array}{l}29 \\
(17)\end{array}$ & 0 & 54 (76) & 0 & $\begin{array}{l}14 \\
(20)\end{array}$ & $\begin{array}{l}21 \\
(30)\end{array}$ & $17(24)$ & $5(7)$ & $\begin{array}{l}9 \\
(13)\end{array}$ & $5(7)$ & 0 \\
\hline Hobbies & $91(54)$ & $11(7)$ & $\begin{array}{l}23 \\
(14)\end{array}$ & $\begin{array}{l}44 \\
(26)\end{array}$ & 0 & $45(58)$ & 0 & $7(9)$ & $\begin{array}{l}21 \\
(16)\end{array}$ & 27 (35) & $8(10)$ & $\begin{array}{l}19 \\
(25)\end{array}$ & $4(5)$ & 1 \\
\hline Driving & $89(53)$ & $2(1)$ & $\begin{array}{l}29 \\
(17)\end{array}$ & $\begin{array}{l}49 \\
(29)\end{array}$ & 0 & $25(31)$ & 0 & $\begin{array}{l}9 \\
(11)\end{array}$ & $\begin{array}{l}7 \\
(9)\end{array}$ & $4(5)$ & $11(14)$ & $\begin{array}{l}41 \\
(51)\end{array}$ & $\begin{array}{l}8 \\
(10)\end{array}$ & 0 \\
\hline Outings & $87(51)$ & $16(9)$ & $\begin{array}{l}30 \\
(18)\end{array}$ & $\begin{array}{l}36 \\
(21)\end{array}$ & 0 & $57(70)$ & 0 & $\begin{array}{l}9 \\
(11)\end{array}$ & $\begin{array}{l}26 \\
(32)\end{array}$ & $19(23)$ & $4(5)$ & $\begin{array}{l}20 \\
(24)\end{array}$ & $4(5)$ & 0 \\
\hline Visiting & $92(54)$ & $12(7)$ & $\begin{array}{l}34 \\
(20)\end{array}$ & $\begin{array}{l}31 \\
(18)\end{array}$ & 0 & $37(48)$ & 0 & $\begin{array}{l}10 \\
(13)\end{array}$ & $\begin{array}{l}11 \\
(14)\end{array}$ & $13(17)$ & $10(13)$ & $\begin{array}{l}29 \\
(38)\end{array}$ & $4(5)$ & 0 \\
\hline Home & $63(37)$ & 1 (1) & $8(5)$ & $\begin{array}{l}96 \\
(57)\end{array}$ & 1 & $11(10)$ & 0 & $4(4)$ & $\begin{array}{l}3 \\
(3)\end{array}$ & $5(5)$ & $6(6)$ & $\begin{array}{l}63 \\
(59)\end{array}$ & $\begin{array}{l}25 \\
(24)\end{array}$ & 0 \\
\hline $\begin{array}{l}\text { Indepen- } \\
\text { dence }\end{array}$ & $52(31)$ & $2(1)$ & $\begin{array}{l}25 \\
(15)\end{array}$ & $\begin{array}{l}89 \\
(53)\end{array}$ & 1 & $43(37)$ & 0 & $\begin{array}{l}10 \\
(9)\end{array}$ & $\begin{array}{l}18 \\
(15)\end{array}$ & $15(13)$ & $14(12)$ & $\begin{array}{l}45 \\
(39)\end{array}$ & $\begin{array}{l}15 \\
(13)\end{array}$ & 0 \\
\hline Extra & 141 (83) & 1 (1) & $9(5)$ & $\begin{array}{l}18 \\
(11)\end{array}$ & 0 & $22(79)$ & 0 & $2(7)$ & $\begin{array}{l}10 \\
(36)\end{array}$ & $5(18)$ & $4(14)$ & $\begin{array}{l}3 \\
(11)\end{array}$ & $\begin{array}{l}4 \\
(14)\end{array}$ & 0 \\
\hline
\end{tabular}

* Missing values at baseline are all due to the interviewer accidentally forgetting to indicate the option on the answer sheet after the interview, except for 'enjoying life', which was unknown by the participant. 
Table 8. P-BAS-P Follow-up and change $n=136$

Page $14 / 28$ 


\begin{tabular}{|c|c|c|c|c|c|c|c|c|c|c|c|}
\hline & $\mathrm{n}$ & $\begin{array}{l}\text { Very } \\
\text { bad }\end{array}$ & Bad & Mediocre & $\begin{array}{l}\text { Satis- } \\
\text { factory }\end{array}$ & Good & $\begin{array}{l}\text { Very } \\
\text { good }\end{array}$ & $\begin{array}{l}\text { Mis- } \\
\text { sing }\end{array}$ & $\begin{array}{l}\text { Missing } \\
\text { Corona }\end{array}$ & $\begin{array}{l}\text { Change } \\
\text { (F-B) }\end{array}$ & Score \\
\hline Better & 130 & 0 & $3(2)$ & $31(24)$ & $30(23)$ & $\begin{array}{l}58 \\
(43)\end{array}$ & $8(6)$ & 0 & & $\begin{array}{l}\text { Mean: } 1.35 \\
\text { SD: } 1.54 \\
\text { Range: }-2- \\
5\end{array}$ & $\begin{array}{l}\text { Mean: } \\
0.44 \\
\text { SD: } 1.48 \\
\text { Range: -3 - } \\
4\end{array}$ \\
\hline Energy & 116 & $1(1)$ & $7(6)$ & $40(35)$ & $25(22)$ & $\begin{array}{l}40 \\
(35)\end{array}$ & $3(3)$ & 0 & & $\begin{array}{l}\text { Mean: } 1.15 \\
\text { SD: } 1.44 \\
\text { Range: }-2- \\
4\end{array}$ & $\begin{array}{l}\text { Mean: } \\
0.28 \\
\text { SD: } 1.36 \\
\text { Range: -3 - } \\
3\end{array}$ \\
\hline Pain & 57 & $1(2)$ & 0 & $15(27)$ & $8(14)$ & $\begin{array}{l}24 \\
(45)\end{array}$ & $7(13)$ & 1 & & $\begin{array}{l}\text { Mean: } 1.76 \\
\text { SD: } 1.65 \\
\text { Range: }-2- \\
5\end{array}$ & $\begin{array}{l}\text { Mean: } \\
0.93 \\
\text { SD: } 1.49 \\
\text { Range: -3 - } \\
4\end{array}$ \\
\hline Bowel movements & 28 & $1(4)$ & $1(4)$ & $2(7)$ & $6(22)$ & $\begin{array}{l}14 \\
(52)\end{array}$ & $3(11)$ & 1 & & $\begin{array}{l}\text { Mean: } 0.90 \\
\text { SD: } 1.67 \\
\text { Range: }-1 \text { - } \\
4\end{array}$ & $\begin{array}{l}\text { Mean: } \\
0.24 \\
\text { SD: } 1.48 \\
\text { Range: -2 - } \\
3\end{array}$ \\
\hline $\begin{array}{l}\text { Shortness } \\
\text { of breath }\end{array}$ & 78 & 0 & $4(5)$ & $24(31)$ & $13(17)$ & $\begin{array}{l}32 \\
(41)\end{array}$ & $5(6)$ & 0 & & $\begin{array}{l}\text { Mean: } 1.52 \\
\text { SD: } 1.46 \\
\text { Range: }-2- \\
4\end{array}$ & $\begin{array}{l}\text { Mean: } \\
0.59 \\
\text { SD: } 1.42 \\
\text { Range: -3 - } \\
3\end{array}$ \\
\hline Walking & 89 & $2(2)$ & $5(6)$ & $27(31)$ & $21(24)$ & $\begin{array}{l}30 \\
(34)\end{array}$ & $3(3)$ & 1 & & $\begin{array}{l}\text { Mean: } 1.19 \\
\text { SD: } 1.57 \\
\text { Range: }-3- \\
4\end{array}$ & $\begin{array}{l}\text { Mean: } \\
0.33 \\
\text { SD: } 1.49 \\
\text { Range: -4 - } \\
3\end{array}$ \\
\hline Appetite & 40 & $1(3)$ & $2(5)$ & $5(13)$ & $5(13)$ & $\begin{array}{l}21 \\
(53)\end{array}$ & $6(15)$ & 0 & & $\begin{array}{l}\text { Mean: } 1.00 \\
\text { SD: } 1.41 \\
\text { Range: }-1 \text { - } \\
4\end{array}$ & $\begin{array}{l}\text { Mean: } \\
0.38 \\
\text { SD: } 1.23 \\
\text { Range: -2 - } \\
3\end{array}$ \\
\hline $\begin{array}{l}\text { Knowing what is } \\
\text { wrong }\end{array}$ & 58 & $1(2)$ & $4(7)$ & $2(4)$ & $12(21)$ & $\begin{array}{l}26 \\
(46)\end{array}$ & $12(21)$ & 1 & & $\begin{array}{l}\text { Mean: } 1.32 \\
\text { SD: } 1.74 \\
\text { Range: }-2- \\
5\end{array}$ & $\begin{array}{l}\text { Mean: } \\
0.32 \\
\text { SD: } 1.74 \\
\text { Range: -3 - } \\
4\end{array}$ \\
\hline Curing & 132 & 0 & $6(5)$ & $26(20)$ & $25(19)$ & $\begin{array}{l}53 \\
(41)\end{array}$ & $19(15)$ & 3 & & $\begin{array}{l}\text { Mean: } 1.63 \\
\text { SD: } 1.46 \\
\text { Range: }-2- \\
5\end{array}$ & $\begin{array}{l}\text { Mean: } \\
0.84 \\
\text { SD: } 1.49 \\
\text { Range: }-3 \text { - } \\
5\end{array}$ \\
\hline Alive & 117 & n.a. & n.a. & n.a. & n.a. & n.a. & n.a. & n.a. & n.a. & n.a. & $\begin{array}{l}\text { Mean: } 0 \\
\text { SD: } 0 \\
\text { Range: } 0\end{array}$ \\
\hline Enjoy & 105 & $1(1)$ & $1(1)$ & $15(14)$ & $19(18)$ & $\begin{array}{l}47 \\
(45)\end{array}$ & $21(20)$ & 1 & & $\begin{array}{l}\text { Mean: } 1.05 \\
\text { SD: } 1.68 \\
\text { Range: }-4 \text { - } \\
5\end{array}$ & $\begin{array}{l}\text { Mean: } \\
0.39 \\
\text { SD: } 1.54\end{array}$ \\
\hline
\end{tabular}




\begin{tabular}{|c|c|c|c|c|c|c|c|c|c|c|c|}
\hline & & & & & & & & & & & $\begin{array}{l}\text { Range: -4 - } \\
4\end{array}$ \\
\hline Groceries & 74 & $4(6)$ & $6(9)$ & $9(13)$ & $8(11)$ & $\begin{array}{l}38 \\
(54)\end{array}$ & $6(9)$ & 1 & 3 & $\begin{array}{l}\text { Mean: } 0.89 \\
\text { SD: } 1.67 \\
\text { Range: }-4 \text { - } \\
5\end{array}$ & $\begin{array}{l}\text { Mean: } \\
0.29 \\
\text { SD: } 1.50 \\
\text { Range: -5 - } \\
4\end{array}$ \\
\hline Wash and dress & 55 & 0 & $4(7)$ & $5(9)$ & $5(9)$ & $\begin{array}{l}32 \\
(58)\end{array}$ & $9(16)$ & 0 & & $\begin{array}{l}\text { Mean: } 0.85 \\
\text { SD: } 1.46 \\
\text { Range: }-2- \\
5\end{array}$ & $\begin{array}{l}\text { Mean: } \\
0.36 \\
\text { SD: } 1.34 \\
\text { Range: -2 - } \\
5\end{array}$ \\
\hline Garden & 54 & $3(6)$ & $\begin{array}{l}7 \\
(14)\end{array}$ & $8(16)$ & $10(7)$ & $\begin{array}{l}17 \\
(34)\end{array}$ & $5(10)$ & 4 & & $\begin{array}{l}\text { Mean: } 0.85 \\
\text { SD: } 1.67 \\
\text { Range: }-3- \\
5\end{array}$ & $\begin{array}{l}\text { Mean: } \\
0.06 \\
\text { SD: } 1.51 \\
\text { Range: }-3 \text { - } \\
4\end{array}$ \\
\hline Sports & 62 & $3(7)$ & $\begin{array}{l}8 \\
(17)\end{array}$ & $8(17)$ & $8(17)$ & $\begin{array}{l}14 \\
(30)\end{array}$ & $5(11)$ & 4 & 12 & $\begin{array}{l}\text { Mean: } 0.78 \\
\text { SD: } 1.93 \\
\text { Range: }-4 \text { - } \\
4\end{array}$ & $\begin{array}{l}\text { Mean: } \\
0.05 \\
\text { SD: } 1.73 \\
\text { Range: -4 - } \\
3\end{array}$ \\
\hline Hobbies & 72 & $2(3)$ & $2(3)$ & $11(18)$ & $8(13)$ & $\begin{array}{l}30 \\
(48)\end{array}$ & $9(15)$ & 5 & 5 & $\begin{array}{l}\text { Mean: } 0.64 \\
\text { SD: } 1.68 \\
\text { Range: }-2- \\
5\end{array}$ & $\begin{array}{l}\text { Mean: } \\
0.45 \\
\text { SD: } 1.55 \\
\text { Range: -3 - } \\
4\end{array}$ \\
\hline Driving & 74 & $5(7)$ & $4(6)$ & $3(4)$ & $3(4)$ & $\begin{array}{l}42 \\
(58)\end{array}$ & $16(22)$ & 1 & & $\begin{array}{l}\text { Mean: } 0.51 \\
\text { SD: } 1.69 \\
\text { Range: }-3 \text { - } \\
5\end{array}$ & $\begin{array}{l}\text { Mean: } \\
0.18 \\
\text { SD: } 1.49 \\
\text { Range: -3 - } \\
4\end{array}$ \\
\hline Outings & 71 & 0 & $2(4)$ & $13(29)$ & $6(13)$ & $\begin{array}{l}19 \\
(42)\end{array}$ & $5(11)$ & 2 & 24 & $\begin{array}{l}\text { Mean: } 1.05 \\
\text { SD: } 1.90 \\
\text { Range: }-3- \\
4\end{array}$ & $\begin{array}{l}\text { Mean: } \\
0.33 \\
\text { SD: } 1.68 \\
\text { Range: -3 - } \\
3\end{array}$ \\
\hline Visiting & 69 & $1(2)$ & $1(2)$ & $4(8)$ & $8(17)$ & $\begin{array}{l}31 \\
(65)\end{array}$ & $3(6)$ & 1 & 20 & $\begin{array}{l}\text { Mean: } 0.98 \\
\text { SD: } 1.66 \\
\text { Range: }-3 \text { - } \\
4\end{array}$ & $\begin{array}{l}\text { Mean: } \\
0.49 \\
\text { SD: } 1.38 \\
\text { Range: -3 - } \\
3\end{array}$ \\
\hline Home & 96 & $1(1)$ & 0 & $1(1)$ & $7(7)$ & $\begin{array}{l}68 \\
(71)\end{array}$ & $19(20)$ & 0 & & $\begin{array}{l}\text { Mean: } 0.18 \\
\text { SD: } 1.17 \\
\text { Range: }-4 \text { - } \\
4\end{array}$ & $\begin{array}{l}\text { Mean: } \\
0.11 \\
\text { SD: } 1.12 \\
\text { Range: -4 - } \\
4\end{array}$ \\
\hline Indepen-dence & 106 & 0 & $2(2)$ & $8(8)$ & $14(13)$ & $\begin{array}{l}65 \\
(61)\end{array}$ & $17(16)$ & 0 & & $\begin{array}{l}\text { Mean: } 0.79 \\
\text { SD: } 2.45 \\
\text { Range: }-2- \\
5\end{array}$ & $\begin{array}{l}\text { Mean: } \\
0.45 \\
\text { SD: } 1.39 \\
\text { Range: -3 - } \\
4\end{array}$ \\
\hline Extra & 20 & $2(14)$ & $1(7)$ & $1(7)$ & $3(21)$ & $7(50)$ & 0 & 1 & 5 & $\begin{array}{l}\text { Mean: } 0.50 \\
\text { SD: } 1.65\end{array}$ & $\begin{array}{l}\text { Mean: } \\
-0.29 \\
\text { SD: } 1.74\end{array}$ \\
\hline
\end{tabular}


$\mathrm{SD}=$ standard deviation

\section{Reliability}

Baseline Questions. For the test-retest reliability, 62 participants were approached. In twelve cases, the participant refused the retest, resulting in 50 participants performing a baseline test-retest reliability. In 45 cases the retest was performed by another interviewer and in five cases by the same interviewer.

Of the 21 specified goals from which participants could select, the number of discrepancies between test and retest per participant ranged from zero to a maximum of eleven ( $52 \%$ of the number of goals) with a median of $5(24 \%)$. Of the total of 242 discrepancies, the goal was selected only during the test 87 (36\%) times, and in $155(64 \%)$ cases only during the retest.

Item level agreement is included in Additional File 4.

Forty-one retest participants had a follow-up. The $\mathrm{PBI}_{1}$ test of the participants who had a baseline retest ranged from -1.12 to 2.60 , with a mean of 0.55 and standard deviation (SD) of 0.83 . The $\mathrm{PBI}_{1}$ of the retest ranged from -1.05 to 2.45 , with a mean of 0.46 and of SD 0.82 . The ICC between $\mathrm{PBI}_{1}$ of test and retest was $0.76(95 \% \mathrm{Cl} 0.59 ; 0.86)$.

The $\mathrm{PBI}_{2}$ test of the participants who had a baseline retest ranged from -1.13 to 2.62 , with a mean of 0.56 and SD 0.84 . The $\mathrm{PBI}$ of the retest ranged from -1.00 to 2.45 , with a mean of 0.49 and an SD of 0.84 . The ICC between $\mathrm{PBI}_{2}$ of test and retest was $0.73(95 \% \mathrm{Cl} 0.54 ; 0.85)$.

Follow-up Questionnaire. For the follow-up test-retest reliability, 90 participants were approached. In seventeen cases the participant refused the retest, six times the participant could not be reached, one participant was sick at the moment of retest and for six it was unknown why the retest was not performed. Finally, 60 participants performed a test-retest of the follow-up questionnaire. Nine participants indicated their situation had changed between test and retest and were removed from analysis, resulting in 51 retests. Median time between test and retest was seven days. In 36 cases the retest was performed by another interviewer and in fifteen cases by the same interviewer.

The agreement on item level is included in Additional File 5.

For the calculation of the $\mathrm{PBI}$, we excluded one case, because only one out of eighteen answers of the retest was saved in the computer system. The $\mathrm{PBI}$ test of the participants who had a follow-up retest ranged from -1.04 to 2.87 , with a mean of 0.26 and an $\mathrm{SD}$ of 0.70 . The PBI ${ }_{1}$ of the retest follow-up ranged from -1.26 to 2.59 , with a mean of 0.27 and an SD of 0.72 . The ICC between the $\mathrm{PBI}_{1}$ of the test and retest follow-up was 0.86 (95\% $\left.\mathrm{Cl} 0.77 ; 0.92\right)$.

The $\mathrm{PBI}_{2}$ of the participants with a follow-up retest ranged from -1.00 to 2.91 , with a mean of 0.27 and an $\mathrm{SD}$ of 0.69 . The $\mathrm{PBI}$ of the retest follow-up ranged from -1.25 to 2.58 , with a mean of 0.27 and an SD of 0.71 . The ICC between the $\mathrm{PBI}_{2}$ of the test and retest follow-up was 0.85 (95\% $\mathrm{Cl} 0.76 ; 0.92$ ).

\section{Validity}

Importance of Goals. All hypotheses, except for hypothesis 11, were confirmed. Table 3 shows the test statistics and complete descriptive information is shown in Additional file 6. The hypothesis for 'bowel movement' could not be calculated because of too low cell frequencies.

The 50 cases selected for the open question mentioned 98 goals in total. Of these, 13 goals could not be coded as an item in the P-BAS-P because they did not exist in the P-BAS-P, and were therefore coded as 'other'. We consequently analysed the agreement between the codes and the answers given in the PBAS-P of 85 goals and found an agreement of $89 \%$. An overview of the number of items coded and the amount of agreement is given in Table 9 .

The number of confirmed hypotheses regarding importance of goals exceeded the threshold for validity.

Table 9. Coding of open questions and agreement with P-BAS-P in descending order of frequency 


\begin{tabular}{|c|c|c|c|}
\hline Code & Frequency coded & Agreement n (\%) & No agreement $\mathrm{n}(\%)$ \\
\hline Curing & 18 & $17(94)$ & $1(6)$ \\
\hline Other & 13 & n.a. & n.a. \\
\hline Alive & 8 & $8(100)$ & 0 \\
\hline Walking & 7 & $7(100)$ & 0 \\
\hline Energy & 7 & $7(100)$ & 0 \\
\hline Hobbies & 7 & $7(100)$ & 0 \\
\hline Sports & 6 & $5(83)$ & $1(17)$ \\
\hline Outings & 6 & $4(67)$ & $2(33)$ \\
\hline Pain & 5 & $3(60)$ & $2(40)$ \\
\hline Shortness of breath & 4 & $4(100)$ & 0 \\
\hline Home & 4 & $3(75)$ & $1(25)$ \\
\hline Independence & 3 & $1(33)$ & $2(67)$ \\
\hline Knowing what is wrong & 3 & $3(100)$ & 0 \\
\hline Groceries & 2 & $2(100)$ & 0 \\
\hline Enjoy & 2 & $2(100)$ & 0 \\
\hline Better & 1 & $1(100)$ & 0 \\
\hline Garden & 1 & $1(100)$ & 0 \\
\hline Visiting & 1 & $1(100)$ & 0 \\
\hline Driving & 0 & n.a. & n.a. \\
\hline Bowel movements & 0 & n.a. & n.a. \\
\hline Appetite & 0 & n.a. & n.a. \\
\hline Wash and dress & 0 & n.a. & n.a. \\
\hline Total & 98 & 76 (89) & $9(11)$ \\
\hline
\end{tabular}

Status Baseline, Follow-up, and Change. As seen in Table 4, all correlations between baseline, follow-up status and the related constructs, are in the direction hypothesised, but from baseline correlations, only four were strong enough and from follow-up six were strong enough to confirm the hypotheses. Of the correlations between change scores, two were strong enough to confirm the hypotheses. For the item 'sports', the correlation was in the opposite direction than was hypothesised. As only the minimum of six confirmed hypotheses was reached for the follow-up status, this was the only moment where the status question was considered valid.

\section{Responsiveness}

Of the 50 cases selected at baseline for comparing open questions, 46 had a follow-up. This resulted in 61 dyads of coded open goals and P-BAS-P items with follow-ups. The correlation between the answers on the open question and the corresponding P-BAS-P score was 0.26 and therefore the hypothesis was rejected.

$\mathrm{PBI}_{1}$ ranged from -1.63 to 2.87 , with a mean of 0.31 and an $\mathrm{SD}$ of 0.80 and $\mathrm{PBI}_{2}$ ranged from -1.94 to 2.91 , with a mean of 0.32 and an $\mathrm{SD}$ of 0.81 . For the anchor question 'How much have you benefited from the admission?' ten (7\%) participants did not know what to answer. Of the valid responses, ten (8\%) of the participants answered 'not at all', five (4\%) 'a little bit', twenty (15\%) 'somewhat', 45 (36\%) much, and 46 (37\%) very much. The Spearman's correlation coefficient between $\mathrm{PBI}_{1}$ and the anchor question was 0.267 , between $\mathrm{PBI}_{2}$ and the anchor question 0.272 .

After coding the explanations participants gave to the anchor question, in 'based on outcomes', or 'based on other grounds', we found that 101 participants (83\%) based their judgements on outcomes, for example 'I have no longer chest pain', and 21 (17\%) on other grounds, for example 'top nurses, they were very correct'. Seven participants gave no explanation. In a selection of participants basing their judgement on outcomes, $\mathrm{PBI}_{1}$ ranged from -1.63 to 2.60 , with a mean of 0.38 and a standard deviation of (SD) 0.79 and $\mathrm{PBI}_{2}$ ranged from -1.94 to 2.62 , with a mean of 0.38 and an $\mathrm{SD}$ of 0.80 . The correlation between $\mathrm{PBI}_{1}$ and anchor question was 0.376 and the correlation between $\mathrm{PBI}_{2}$ and anchor question was 0.389. 
The visual anchor-based minimal important change distribution method was based on the selection of participants basing their judgement on outcomes.

The upper half of figure 4 shows ROC curves of $\mathrm{PBI}_{1}$ with the ROC curve of 'no important benefit' on the left side, with an area under the curve (AUC) of 0.61. The optimal cut-off point for 'no important benefit' was set at a sensitivity value of $84 \%$ and a specificity of $46 \%$, resulting in an MIC of -0.3 points on the $\mathrm{PBI}_{1}$. The right side shows the ROC curve of 'important benefit', with an AUC of 0.63 . The optimal cut-off point for 'important benefit' was set at a sensitivity value of $36 \%$ and a specificity of $95 \%$, resulting in an $\mathrm{MIC}$ of 0.9 points on the $\mathrm{PBI}_{1}$. This means $\mathrm{PBI}_{1}$ values between -0.3 and 0.9 points are considered as 'borderline benefit'.

The lower half of figure 4 shows the ROC curves of $\mathrm{PBI}_{2}$ with the ROC curve of 'no important benefit' on the left side, and an AUC of 0.62 . The optimal cutoff point for 'no important benefit' was set at a sensitivity value of $84 \%$ and a specificity of $54 \%$, resulting in an $\mathrm{MIC}^{\circ}-0.3$ points on the $\mathrm{PBI}$. The right side shows the ROC curve of 'important benefit', with an AUC of 0.63 . The optimal cut-off point for 'important benefit' was set at a sensitivity value of $66 \%$ and a specificity of $66 \%$, resulting in an MIC of 0.2 points on the $\mathrm{PBI}_{2}$. This means the $\mathrm{PBI}_{2}$ values between -0.3 and 0.2 are considered as 'borderline benefit'.

The SEM for $\mathrm{PBI}_{1}$ was 0.41 , resulting in an SDC of 1.1. The SEM for $\mathrm{PBI}_{2}$ was 0.44 , resulting in an SDC of 1.2 .

The anchor-based MIC distribution is displayed in figure 5. As visualised in figure 5, the SDC is larger than the $\mathrm{MIC}$, especially for PBI 2 . There is much overlap between the curves, leading to much misclassification.

\section{Discussion}

In this study, we described the development, feasibility, reliability, validity, responsiveness, and interpretability of the Patient Benefit Assessment scale Picture version (P-BAS-P), a modified version of the P-BAS HOP, which was designed to identify the goals of the individual patient and to measure his relevant outcomes. The results are mixed.

\section{Feasibility}

The baseline pilot and field tests revealed that the P-BAS-P is feasible, but requires good interviewer's instructions. Some participants needed only a short introduction and little guidance from the interviewer, whereas others needed constant guiding and remembering of the aim. The pictures were considered helpful by the participants. A review recommended that different viewers may interpret pictures differently, so guiding is always needed with these kinds of tools (8).

The fact that many interviews were not conducted on the day of admission was potentially problematic, since the (health) status of participants changed considerably and participants had to recall their situation as it was earlier on the day of admission. For the follow-up, we chose format one, where participants were asked how their status per item was at that moment since the pilot revealed this was easily understood.

When comparing the baseline descriptive statistics of the P-BAS-P with the earlier version of the P-BAS HOP (6), some remarkable differences are seen. With the P-BAS-P more goals are selected at minimum 'somewhat important': in the P-BAS HOP, the median number of goals selected by participants was five, with eleven participants not selecting any goal. In the current P-BAS-P, the median number of goals selected was twelve with a minimum of three goals selected per participant. It seems that the threshold to selecting a goal is lowered by differentiating between prevention, preservation, and improvement, and by leaving out the first step in which participants are asked whether they were experiencing difficulty with a subject. Participants might therefore select goals which were not relevant for them, although in the P-BAS HOP participants often stated in the follow-up that a certain goal was not applicable for them, while this was not the case in the current P-BAS-P. Other differences between descriptive statistics of the two versions are that the current P-BAS-P shows more diversity in importance items and an extra goal is mentioned more frequently (28 out of 169 versus 19 out of 451 ). This could mean that participants are more involved with the P-BAS-P because they have to place the cards on the answer sheets themselves, instead of just answering questions given by an interviewer. This is in line with other research where was found that patients were more likely to read text when pictures were added or patients were more engaged by the inclusion of pictures $(8,22)$.

\section{Reliability}

The ICC of the PBI is acceptable, with the ICC on follow-up being more satisfactory. This is because when calculating the PBI for test and retest at follow-up, only the status varies; while at baseline, the status, as well as the importance and the choice between prevention/preservation and improvement, vary. Moreover, participants had to remember their health status often from two to four days prior and are assumed to be in a more unstable situation during baseline than follow-up.

When examining the reliability at the item level (additional files 4 and 5), a broad variation in kappa values is seen, with the reliability of status being highest, especially at follow-up and of the choice between prevention/preservation and improvement being lowest. This suggests that the question about status is more easily understood, or is least ambiguous to explain by the interviewer. A change in the choice between prevention/preservation and improvement is often caused by a change in status. For example, a participant said during the test that the status of an item was 'good' and chose preservation, while stating at retest it was 'mediocre', and chose improvement. This makes the test-retest disagreement more logical.

The reliability of the question about the importance of goals is moderate. This could also be explained because choosing which goals or items are relevant, is very different from, for example, assessing health status. When comparing the P-BAS-P with other instruments where participants choose their own 
domains, it is seen that choosing other domains in the retest is rather common. In the 'schedule for the evaluation of individual quality of life' (SEIQoL-DW), $35 \%$ to $81 \%$ chose new domains $(23,24)$. In the Patient-Generated Index (PGI) participants have to choose a maximum of five domains and the mean number of changes in the retest was 1.7 and $21 \%$ of the participants chose three to five new domains $(24,25)$.

The baseline retest ICC of the P-BAS-P is comparable with the former P-BAS HOP $\left(0.76\left(\mathrm{PBI}_{1}\right) / 0.73\left(\mathrm{PBI}_{2}\right)\right.$ versus 0.77$)(6)$, but in the former version only the importance of goals varied, while in this version the choice between prevention/preservation/improvement and the status also varied. In contrast, the followup retest ICC has improved from 0.62 to $0.86 / 0.85$ between the two versions, suggesting that the adaptations were an improvement for the reliability. Unfortunately, the reliability of the baseline retest had a large impact on the SEM and consequently, the SDC. This is clearly visible in Figure 5: $82 \%$ of the $\mathrm{PBI}_{1}$-values and $84 \%$ of the $\mathrm{PBI}_{2}$-values fall within the measurement error, and the SDC is far beyond the MIC values.

\section{Validity}

Validity data showed that the selection of goals was logically based on the impairments participants had. However, there are two signs that, in rare cases, the selection of goals was not logical. The first is that some participants indicated not having a problem or limitation with a subject, but mentioned as a goal to improve that subject. The second is that, in very rare cases, participants stated never having done an activity, such as sporting, but selected this goal.

The data of choice between prevention/preservation or improvement provide two discussion points. First, although the relationships between status and the choice between prevention/preservation or improvement were very strong (data not shown), every goal has from one to seven cases of a status judged as (very) good, but with the goal to improve that status, this gives little to no room for improvement, and has therefore consequences for the validity of the scores. Second, the goal 'return back home' was the only goal where the choice between preservation or improvement was not directly asked to the participant, but depended on the situation from where the participant was admitted and where he/she wanted to return to (see Additional file 1 ). The fact that all eleven participants where the choice 'improvement' was made were living independently, means that the instruction here was not clear to all interviewers.

The validity of the questions regarding 'status' is problematic. In the hypothesised strengths of relationships was already accounted for the fact the P-BAS-P status and other constructs at follow-up both refer to the moment of interview, while at baseline the P-BAS-P asks for the status on the day of admission and the others constructs the moment of interview, which is usually a few days later. Almost all follow-up hypotheses were confirmed, but only half of the baseline hypotheses. Possibly the error caused by different time moments at baseline was larger than expected and this could also have influenced the strength of the relationships of change values. In addition, the unstable situation at baseline could have made the construct assessment more difficult than at follow-up. For exercise or sports, correlations at baseline and follow-up were weak and change scores were in the opposite direction than hypothesised. The related construct was physical activity for at least 30 minutes; this could be any activity, for example going for a walk, but these activities are not always considered as exercise or sports.

\section{Responsiveness}

The correlations between the answers on the open question on follow-up and the corresponding P-BAS-P scores were too weak to support the validity of the scores. When we computed the SDC for only score, so with maintaining the importance weights constant, the SDC was 1.09 . Since most P-BAS-P scores were between -1 and 1 , most fell within the measurement error, which makes the comparison biased. Another explanation as to why the comparison is complicated is that the scales are very different. Even when we leave out all the cases with contrary and half congruent answers (Additional file 7), the correlation would be 0.47 . This is because a 'completely' attained goal can have a score varying from 0 to 3 , which gives rise to doubts about whether the score always reflects the amount of perceived benefit. The goal 'remaining alive', for example, has a standard score of 0 , but as the mean of the scores is 0.31 , the consequence is that having set the goal 'remaining alive', means for most participants that the total PBI is lowered. Although this goal is very important for many people, it is difficult to express into a score and therefore we recommend to leave this specific goal out of the calculation of the PBI.

We compared all answers on the selected open goals and answers on the P-BAS-P (Additional file 7) and found some contradictory answers. This could be explained by the aforementioned problems with baseline validity due to the baseline interview taking place a few days after admission. For example, participants with the goal 'curing' mentioning at baseline that their disease state was '(very) good', which not only gave no or little room for improvement but also questions the validity of the answer '(very) good' at baseline since it is questionable if the cure was even needed. Another explanation could be response shift. An event like a hospitalisation causes a response shift; participants make different cognitive appraisals at different moments, resulting in a recalibration, reprioritisation, and reconceptualisation of goals (26-28). In this study, we used absolute scores for the P-BAS-P ('what is the status now') and relative comparison for answering the goal in the open question, where the participant (implicit) has to compare the situation now with how it was at baseline (1). These different comparisons require different cognitive processes and therefore cause different forms of response shift. In addition, relative comparisons are more susceptible to recall bias and social desirability (29).

This pattern also applies to the comparison of the PBI with the anchor question. The correlation between the PBI and anchor question was medium and too low to be a valid anchor. Weak correlations between anchor and change scores are common (30). According to Cohen (18), correlations in behavioural sciences are rarely high. For this reason, Revicki et al. (31) recommend a correlation of at least 0.30 between anchor and outcome, which we reached, but the price is many misclassifications, as seen in Figure 5.

Other explanations for the moderate correlations are that a single question, which is the characteristic of an anchor question, is less reliable and valid than a multi-item instrument and response shift, especially the phenomenon that the ratings on the anchor correlate more with the follow-up score than with the

Page 20/28 
change score $(30,32,33)$. These findings in the literature are also supported by the explanations to the anchor question given by the participants. When the participant mentioned a concrete attained outcome as an explanation of the amount of benefit, this was usually only one outcome; in almost half of the cases a disease-specific outcome, such as 'infection cured', or 'tumour completely removed'. In most cases, this correlated with the selected goal and score on the corresponding goal. However, participants always selected multiple goals in the P-BAS-P and the scores on the other goals also count in the PBI, while these are not included in the appraisal of the anchor question. The question arises whether the amount of benefit is too complex to capture in only one question or whether the P-BAS-P takes into account too many items that are not relevant for the participant because, in the end, everything turns on whether the disease ameliorated or not and all the other goals that were selected by the participant were selected because the participant was primed by the pictures, but this was not what really mattered. It could also be that the participant gave socially desirable answers, since a hospital is a medical environment, participants judge the benefit of hospitalisation in medical terms because they might think this is expected. Examples of response shift are also seen. For example, one participant stated that he had 'a little bit of benefit' from the hospital admission because he declared that his shortness of breath worsened due to the admission, while according to the P-BAS-P the shortness of breath ameliorated from 'very bad' to 'mediocre'. This is an example of the anchor correlating more with the follow-up answer than the change score.

Another discussion point is the anchor question itself and its answer options. We asked for the amount of benefit on a scale from 'not at all' to 'very much'. Most similar studies use an anchor in which participants can distinguish between no change, several grades of improvement, and several grades of deterioration $(9,20,30,33)$. This means that we had 'not at all' as the bottom line, while ignoring the options of deterioration, while the current PBI, in contrast to the former version, does give negative values.

$\mathrm{PBI}_{2}$ has a slightly better correlation with the anchor question than $\mathrm{PBI}_{1}$, suggesting that the importance of goals counts for the perceived benefit. This is confirmed by the fact that the correlation was lowest when goals were not weighted, with a correlation of 0.259 for the whole sample and 0.362 for the selection of participants basing their judgment on outcomes. However, the consequence is lower reliability since a deviation of importance of goals has more impact on the variation of the $\mathrm{PBI}_{2}$.

The PBI of the former P-BAS-HOP, which was identical to follow-up format two of the current version, which we abandoned, had a correlation of 0.51 with the anchor question and therefore was considered valid (6). This could be due to the fact that the follow-up questions, used to calculate the PBI, and the anchor question were more comparable, using relative comparison and the answer scales were almost identical. Nevertheless, we still think we had good arguments to abandon format two, since the pilot revealed that, in contrast to format one, both the sentences of the follow-up questions were considered too complicated and the timeframes were unclear. We could have tried to specify the timeframe in the questions, but that would have made the questions even more complex. Moreover, other research showed that even when timeframes are specified, these frames were rarely used, on the contrary, participants used for them meaningful timeframes (29).

\section{Limitations}

The main limitation was that the first interview usually took place a few days after admission, sometimes even on the same day as discharge. It is not only unnatural to discuss goals in a late stadium of the admission, it also might have hampered the feasibility, reliability, validity, and responsiveness.

Due to the Corona pandemic, we had to stop the inclusion of new participants. Therefore the sample size is lower than we opted for. Although 136 complete cases are sufficient for the analyses we used, it appeared sometimes to be too few when we analysed on a per-item level. Furthermore, most follow-ups were conducted while we had Corona-measures like staying at home, avoiding visiting other people, and places where many people gather were closed. This made the answering of some questions, especially those about sports, outings, and visiting complicated and probably biased. We placed missing values in cases where participants placed Corona-related remarks, but in cases where participants answered the questions without remarks, the answers were possibly still biased.

Missing values at baseline were caused by the interviewer needing to circle the outcomes on paper while removing the cards, which is sensitive to errors and omissions.

We had a fluctuating team of thirteen interviewers, which not only required significant effort to train and familiarise them in the use of the P-BAS-P, but could also lead to undesirable variation between interviewers. The time between discharge and follow-up was three months, which might be quite long if patients have to indicate the benefit of hospitalisation.

\section{Conclusion And Recommendations}

The P-BAS-P appeared to be a feasible instrument, but there were methodological barriers for the evaluation of the reliability, validity, and responsiveness. We, therefore, recommend further research into the feasibility, reliability, validity, and responsiveness of the P-BAS-P with the first interview preferably before hospitalisation, or, in case of an acute hospital admission, on the first day. Because change scores were hampered by measurement error, recall bias, and response shift, we recommend showing participants their baseline answers again at follow-up (34). To evaluate the responsiveness, we recommend a broader anchor question in which participants can distinguish between no change, several grades of improvement, and several grades of deterioration (33).

\section{Abbreviations}

ADL Activities of Daily Living

AUC Area Under the Curve 
ICC Intraclass Correlation Coefficient

MIC Minimal Important Change

NRS Numeric Rating Scale

P-BAS HOP Patient Benefit Assessment Scale for Hospitalised Older Patients

P-BAS-P Patient Benefit Assessment Scale Picture Version

PBI Patient Benefit Index

ROC Receiver Operating Characteristic

RSCL Rotterdam Symptom Checklist

SF-36 36-Item Short Form Survey Instrument

S Score

SD Standard Deviation

SDC Smallest Detectable Change

TSTI Three-Step Test-Interview

VAS Visual Analogue Scale

VMS Safety Management Programme

W Weight

\section{Declarations}

\section{Ethics approval and consent to participate}

This study was presented to the Medical Ethics Research Committee of the UMCG (file number M16.192615) and the committee confirmed that the Medical Research Involving Human Subjects Act did not apply to the research project. Official approval by the committee was therefore not required.

All participants gave informed consent to participate in the study.

The study was conducted according to the guidelines of the Declaration of Helsinki.

\section{Consent for publication}

Not applicable

\section{Availability of data and material}

The datasets used and/or analysed during the current study are available from the corresponding author on reasonable request

\section{Competing interests}

The authors declare that they have no competing interests

\section{Funding}

This study was funded by an unrestricted grant from the University of Groningen

\section{Authors' contributions}

MJvdK and SEdR designed the study. MJvdK performed the TSTI's, participated in the data collection, supervised the research assistants, and performed the statistical analyses. MJvdK wrote the first draft of the manuscript, GJD and SedR contributed significantly to subsequent manuscript revisions. All authors have read and approved the final version of the manuscript.

\section{Acknowledgements}

We would like to acknowledge the following persons: Senne Trip for her beautiful drawings, Nicole Pluim for the interview transcriptions, Job van der Palen for his statistical advice and Daniël Bosold for his help with text editing. We would like to thank all study participants for answering the questions, sharing 
their stories with us and their feedback on the different versions of the P-BAS-P and the research assistants for their assistance with the data collection.

\section{References}

1. Bowyer A, Royse C. A matter of perspective-Objective versus subjective outcomes in the assessment of quality of recovery. Best Pract Res Clin Anaesthesiol 2018 Sep-Dec;32(3-4):287-294.

2. Wiering B, de Boer D, Delnoij D. Patient involvement in the development of patient-reported outcome measures: a scoping review. Health Expect 2017 Feb;20(1):11-23.

3. Van der Kluit MJ, Dijkstra GJ, de Rooij SE. Goals of older hospitalised patients: a qualitative descriptive study. BMJ open 2019 08/05;9(8):e029993e029993.

4. Wiering B, de Boer D, Delnoij D. Asking what matters: The relevance and use of patient-reported outcome measures that were developed without patient involvement. Health Expect 2017 Dec;20(6):1330-1341.

5. van der Kluit MJ, Dijkstra GJ, van Munster BC, De Rooij S. Development of a new tool for the assessment of patient-defined benefit in hospitalised older patients: the Patient Benefit Assessment Scale for Hospitalised Older Patients (P-BAS HOP). BMJ Open 2020 Nov 23;10(11):e038203-2020-038203.

6. van der Kluit MJ, Dijkstra GJ, de Rooij SE. Reliability and validity of the Patient Benefit Assessment Scale for Hospitalised Older Patients (P-BAS HOP). BMC Geriatr 2021 Mar 1;21(1):149-021-02079-z.

7. Sørensen K, Pelikan JM, Röthlin F, Ganahl K, Slonska Z, Doyle G, et al. Health literacy in Europe: comparative results of the European health literacy survey (HLS-EU). Eur J Public Health 2015 Dec;25(6):1053-1058.

8. Houts PS, Doak CC, Doak LG, Loscalzo MJ. The role of pictures in improving health communication: a review of research on attention, comprehension, recall, and adherence. Patient Educ Couns 2006 May;61(2):173-190.

9. De Vet HCW, Terwee CB, Mokkink LB, Knol DL. Measurement in Medicine. A Practical Guide. 1st ed. Cambridge: Cambridge University Press; 2011.

10. Pool JJM, Hiralal S, Ostelo, Raymond W J G, van der Veer K, de Vet HCW. Added value of qualitative studies in the development of health related patient reported outcomes such as the Pain Coping and Cognition List in patients with sub-acute neck pain. Man Ther 2010;15(1):43-47.

11. Van Der Veer K, Ommundsen R, Hak T, Larsen KS. Meaning Shift of Items in Different Language Versions. A Cross-National Validation Study of the Illegal Aliens Scale. Quality and Quantity 2003;37(2):193-206.

12. Weir JP. Quantifying test-retest reliability using the intraclass correlation coefficient and the SEM. J Strength Cond Res 2005 Feb;19(1):231-240.

13. Terwee CB, Bot SD, de Boer MR, van der Windt DA, Knol DL, Dekker J, et al. Quality criteria were proposed for measurement properties of health status questionnaires. J Clin Epidemiol 2007 Jan;60(1):34-42.

14. Heim N, van Fenema EM, Weverling-Rijnsburger AW, Tuijl JP, Jue P, Oleksik AM, et al. Optimal screening for increased risk for adverse outcomes in hospitalised older adults. Age Ageing 2015 Mar;44(2):239-244.

15. de Haes JC, van Knippenberg FC, Neijt JP. Measuring psychological and physical distress in cancer patients: structure and application of the Rotterdam Symptom Checklist. Br J Cancer 1990 Dec;62(6):1034-1038.

16. Lamers LM, McDonnell J, Stalmeier PF, Krabbe PF, Busschbach JJ. The Dutch tariff: results and arguments for an effective design for national EQ-5D valuation studies. Health Econ 2006 Oct;15(10):1121-1132.

17. Aaronson NK, Muller M, Cohen PD, Essink-Bot ML, Fekkes M, Sanderman R, et al. Translation, validation, and norming of the Dutch language version of the SF-36 Health Survey in community and chronic disease populations. J Clin Epidemiol 1998 Nov;51(11):1055-1068.

18. Cohen J. Statistical power analysis for the behavioral sciences. second ed.: Lawrence Erlbaum Associates; 1988.

19. Crosby RD, Kolotkin RL, Williams GR. Defining clinically meaningful change in health-related quality of life. J Clin Epidemiol 2003 May;56(5):395-407.

20. de Vet HC, Ostelo RW, Terwee CB, van der Roer N, Knol DL, Beckerman H, et al. Minimally important change determined by a visual method integrating an anchor-based and a distribution-based approach. Qual Life Res 2007 Feb;16(1):131-142.

21. de Vet HC, Terwee CB, Ostelo RW, Beckerman H, Knol DL, Bouter LM. Minimal changes in health status questionnaires: distinction between minimally detectable change and minimally important change. Health Qual Life Outcomes 2006 Aug 22;4:54-7525-4-54.

22. Durand MA, Alam S, Grande SW, Elwyn G. 'Much clearer with pictures': using community-based participatory research to design and test a Picture Option Grid for underserved patients with breast cancer. BMJ Open 2016 Feb 2;6(2):e010008-2015-010008.

23. Wettergren L, Kettis-Lindblad A, Sprangers M, Ring L. The use, feasibility and psychometric properties of an individualised quality-of-life instrument: a systematic review of the SEIQoL-DW. Qual Life Res 2009 Aug;18(6):737-746.

24. Aburub AS, Mayo NE. A review of the application, feasibility, and the psychometric properties of the individualized measures in cancer. Qual Life Res 2017 May;26(5):1091-1104.

25. Ruta DA, Garratt AM, Leng M, Russell IT, MacDonald LM. A new approach to the measurement of quality of life. The Patient-Generated Index. Med Care 1994 Nov;32(11):1109-1126.

26. McClimans L, Bickenbach J, Westerman M, Carlson L, Wasserman D, Schwartz C. Philosophical perspectives on response shift. Qual Life Res 2013 Sep;22(7):1871-1878.

27. Sprangers MA, Schwartz CE. Integrating response shift into health-related quality of life research: a theoretical model. Soc Sci Med 1999 Jun;48(11):1507-1515. 
28. Rapkin BD, Schwartz CE. Toward a theoretical model of quality-of-life appraisal: Implications of findings from studies of response shift. Health Qual Life Outcomes 2004 Mar 15;2:14-7525-2-14.

29. Taminiau-Bloem EF, Schwartz CE, van Zuuren FJ, Koeneman MA, Visser MR, Tishelman C, et al. Using a retrospective pretest instead of a conventional pretest is replacing biases: a qualitative study of cognitive processes underlying responses to thentest items. Qual Life Res 2016 Jun;25(6):1327-1337.

30. Terwee CB, Roorda LD, Dekker J, Bierma-Zeinstra SM, Peat G, Jordan KP, et al. Mind the MIC: large variation among populations and methods. J Clin Epidemiol 2010 May;63(5):524-534.

31. Revicki D, Hays RD, Cella D, Sloan J. Recommended methods for determining responsiveness and minimally important differences for patient-reported outcomes. J Clin Epidemiol 2008 Feb;61(2):102-109.

32. Grøvle L, Haugen AJ, Hasvik E, Natvig B, Brox JI, Grotle M. Patients' ratings of global perceived change during 2 years were strongly influenced by the current health status. J Clin Epidemiol 2014 May;67(5):508-515.

33. Kamper SJ, Maher CG, Mackay G. Global rating of change scales: a review of strengths and weaknesses and considerations for design. J Man Manip Ther 2009;17(3):163-170.

34. Guyatt GH, Berman LB, Townsend M, Taylor DW. Should study subjects see their previous responses? J Chronic Dis 1985;38(12):1003-1007.

\section{Figures}
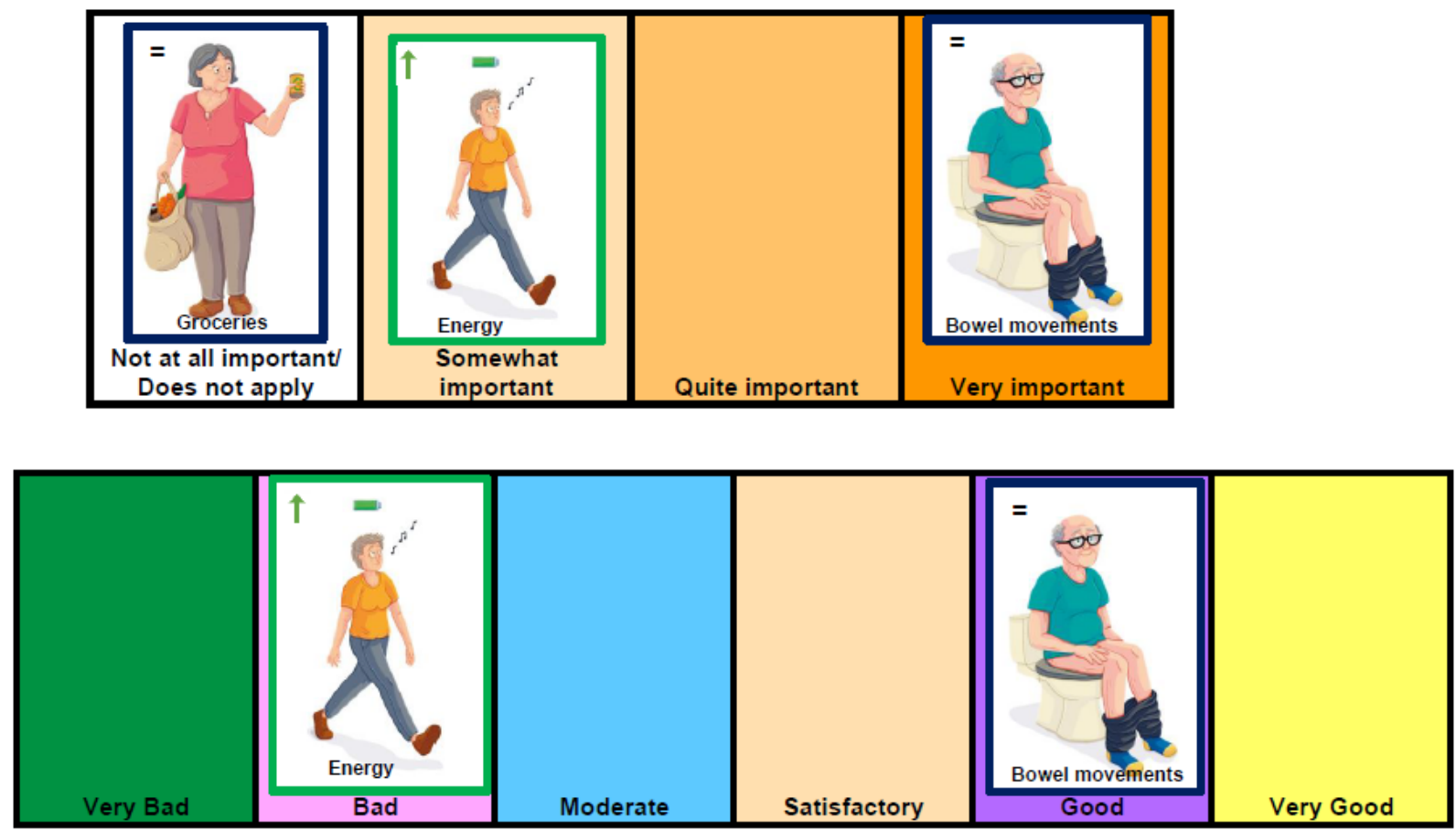

Figure 1

Example of cards and answer sheets of P-BAS-P. Above: answer sheet importance, under: answer sheet status. 


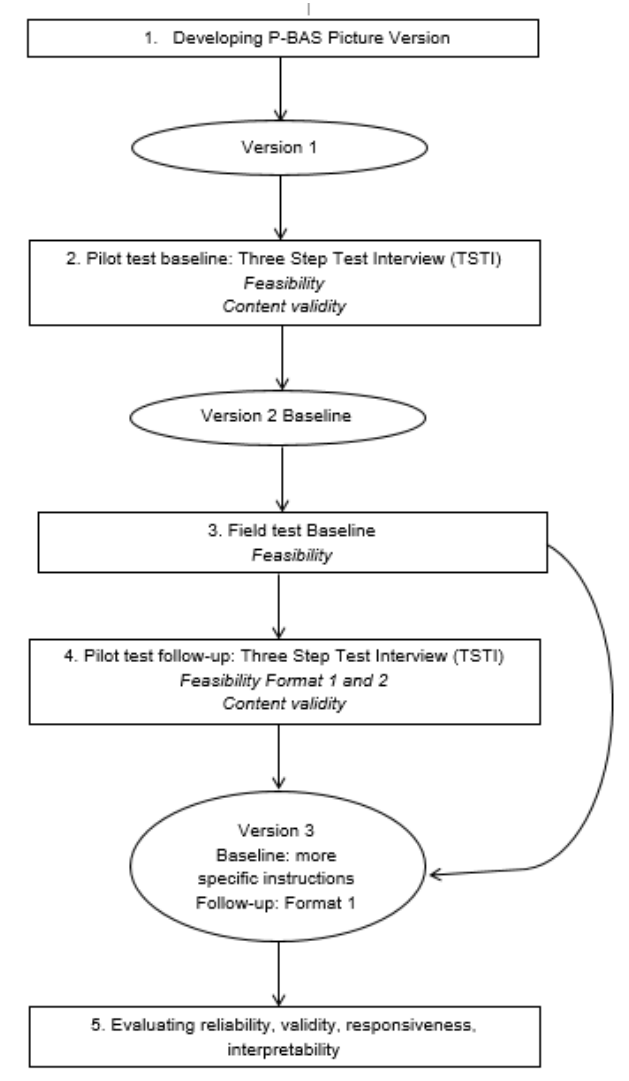

Figure 2

Steps used to develop and test the P-BAS-P 


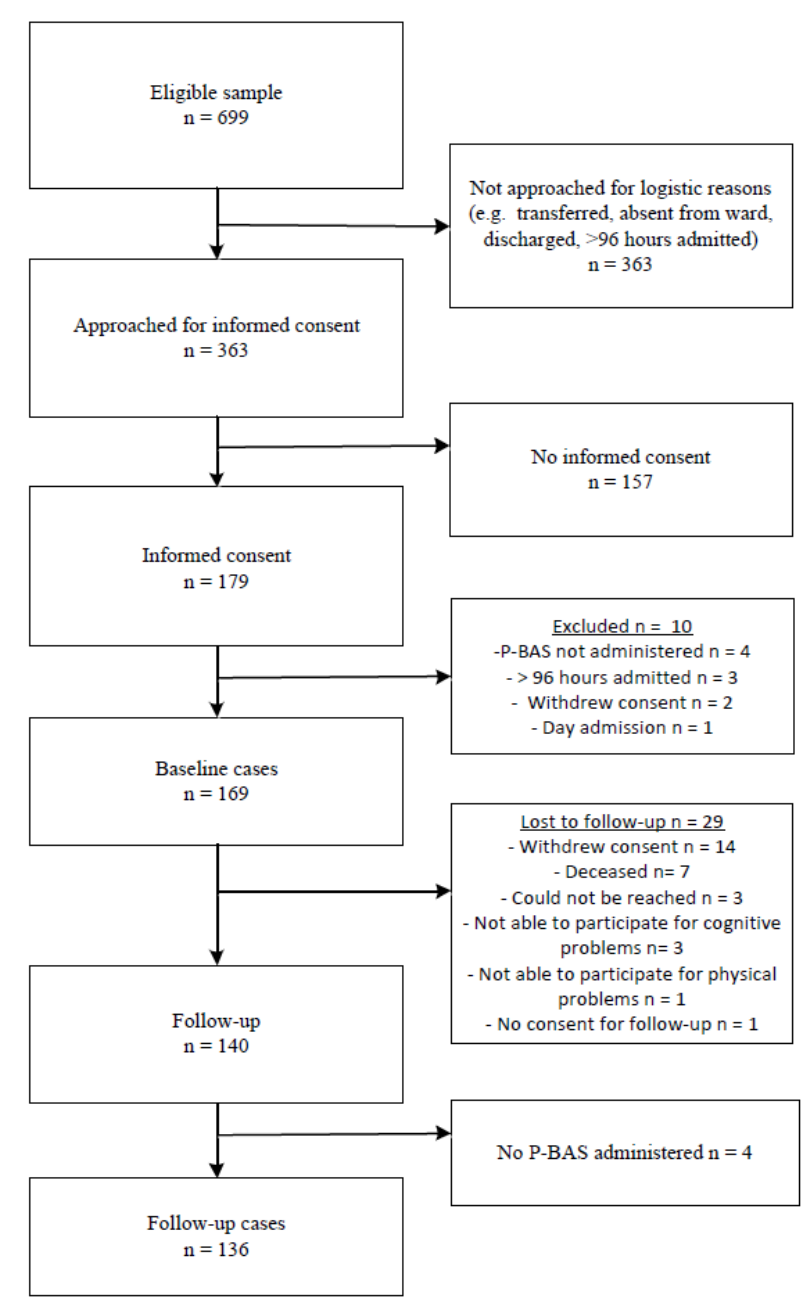

\section{Figure 3}

Flowchart participant inclusion for Evaluating Reliability, Validity, Responsiveness, Interpretability 


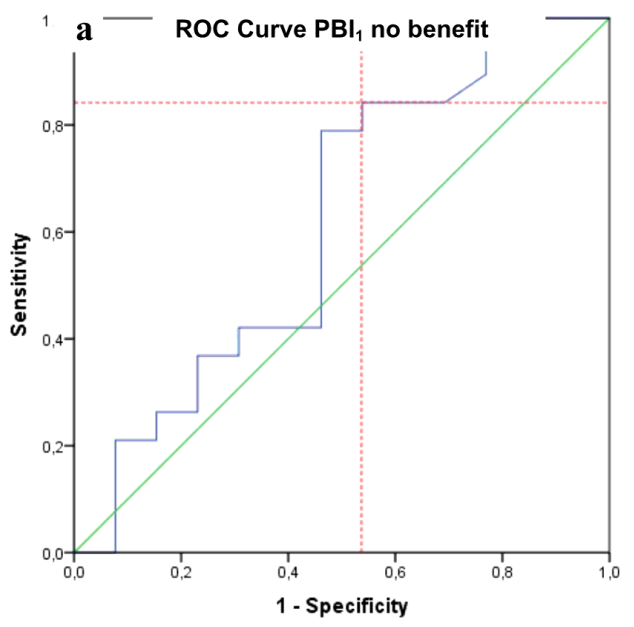

c ROC Curve $\mathrm{PBI}_{2}$ no benefit

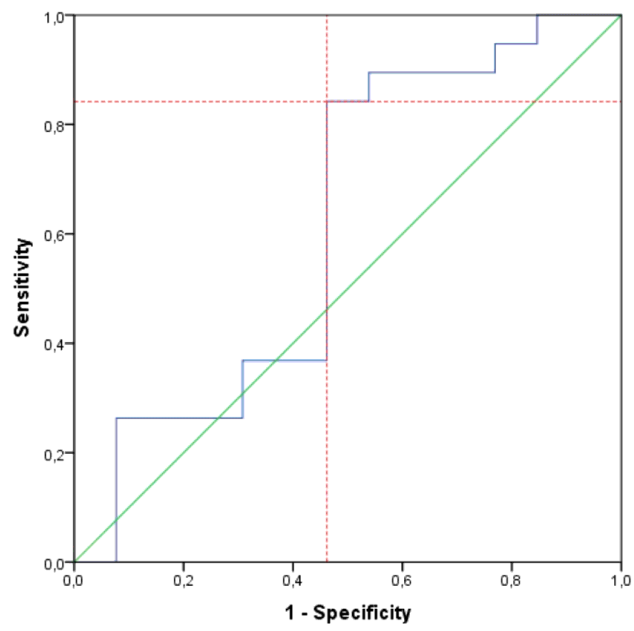

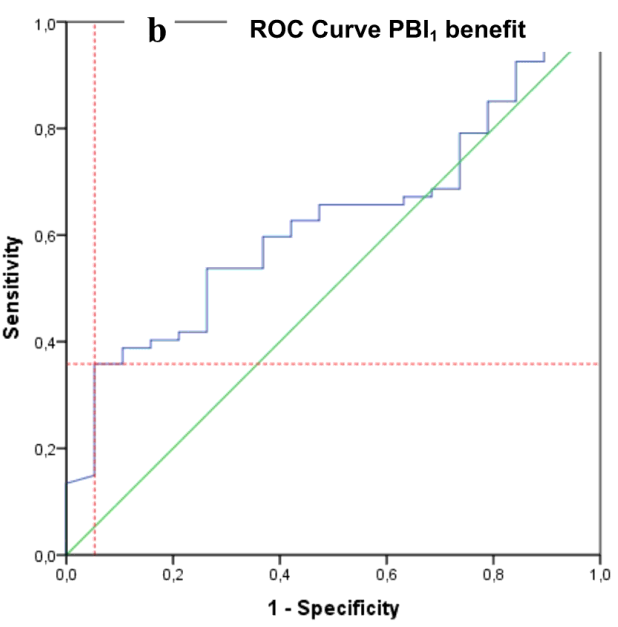

d

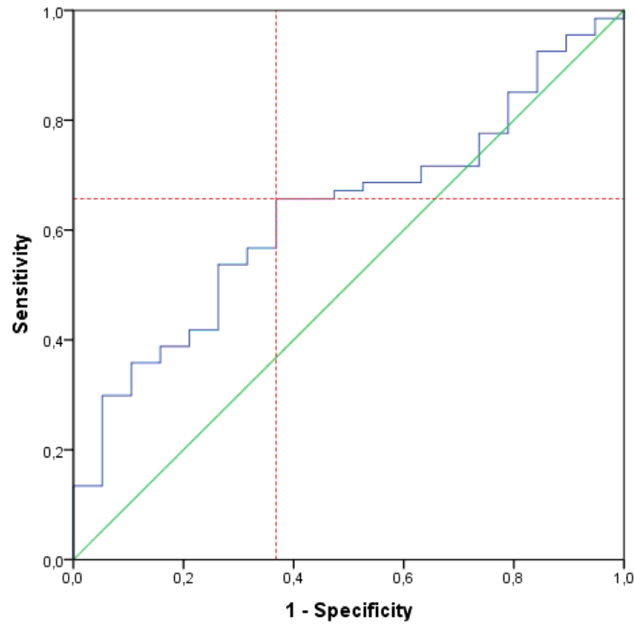

Figure 4

ROC curve with optimal cut-off point. a. PBI1'no benefit' $(n=32, A U C=0.61)$. b. PBI1 'benefit' $(n=86, A U C=0.63) . c . P B I 2$ no benefit' $(n=32, A U C=0.62) . d$. $\mathrm{PBI} 2$ 'benefit' $(\mathrm{n}=86, \mathrm{AUC}=0.63)$. ROC= receiver operating characteristic, PBI= Patient Benefit Index, AUC= Area under de curve

$\mathrm{PBI}_{1}$

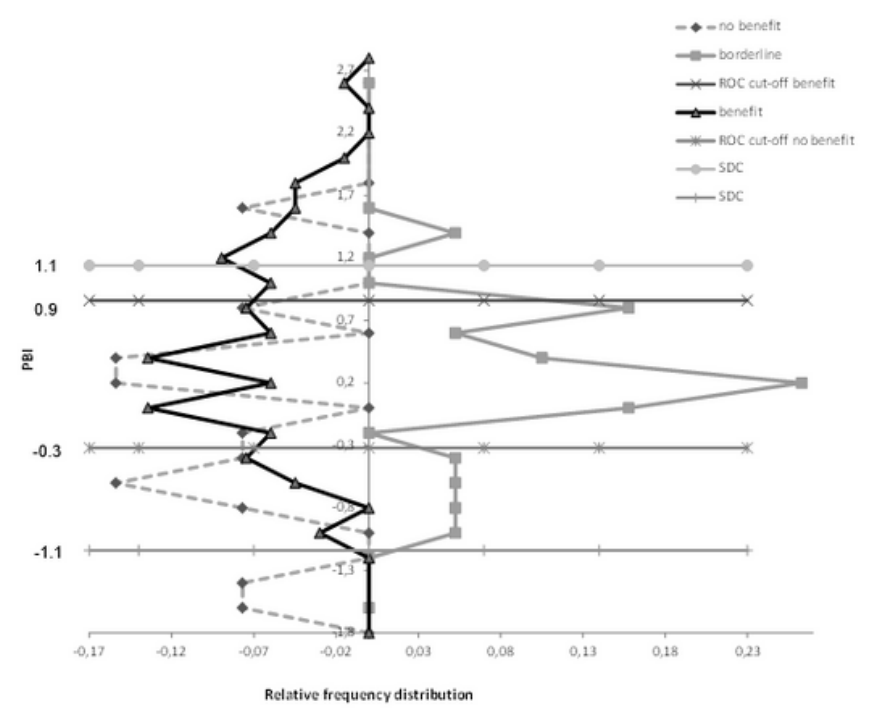

$\mathrm{PBI}_{2}$

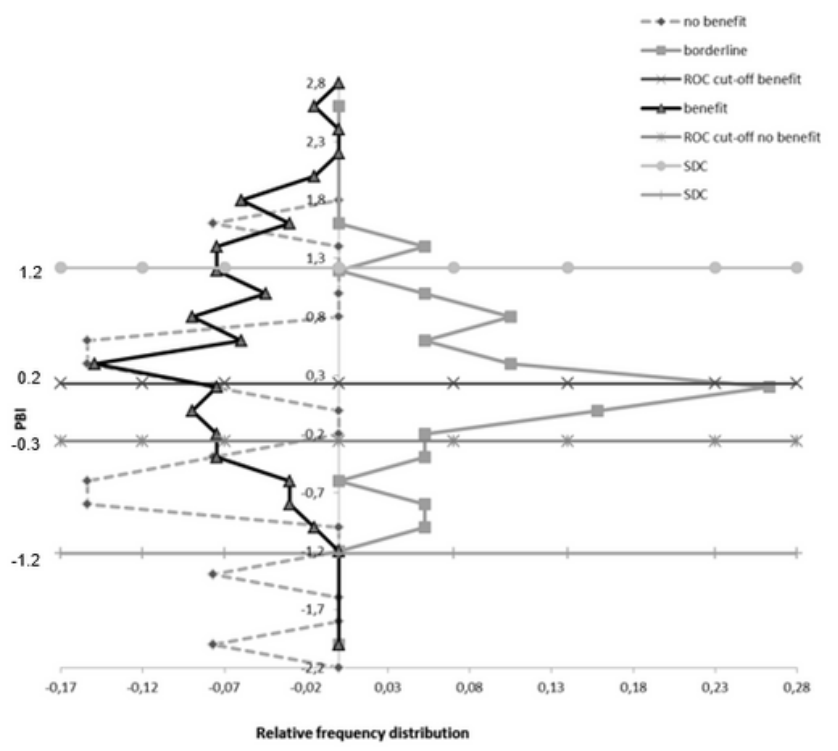

Figure 5 
Anchor-based minimal important change (MIC) distributions. Figure left: PBI1, figure right: PBI2. On left side of figures distribution of participants classified as having relevant benefit benefit (dark line) and no benefit (grey, dashed line) and right side borderline benefit. Cut-off values represent MIC values and SDC. $\mathrm{PBI}=$ Patient Benefit Index, SDC = Smallest Detectable Change

\section{Supplementary Files}

This is a list of supplementary files associated with this preprint. Click to download.

- Additionalfile1.docx

- Additionalfile2.docx

- Additionalfile3.docx

- Additionalfile4.docx

- Additionalfile5.docx

- Additionalfile6.docx

- Additionalfile7.docx 